Document downloaded from:

http://hdl.handle.net/10251/145854

This paper must be cited as:

Abdolpour, H.; Garzón-Roca, J.; Escusa, G.; Sena-Cruz, J.; Barros, J.; Valente, I. (01-0). Composite modular floor prototype for emergency housing applications:Experimental and analytical approach. Journal of Composite Materials. 52(13):1747-1764.

https://doi.org/10.1177/0021998317733318

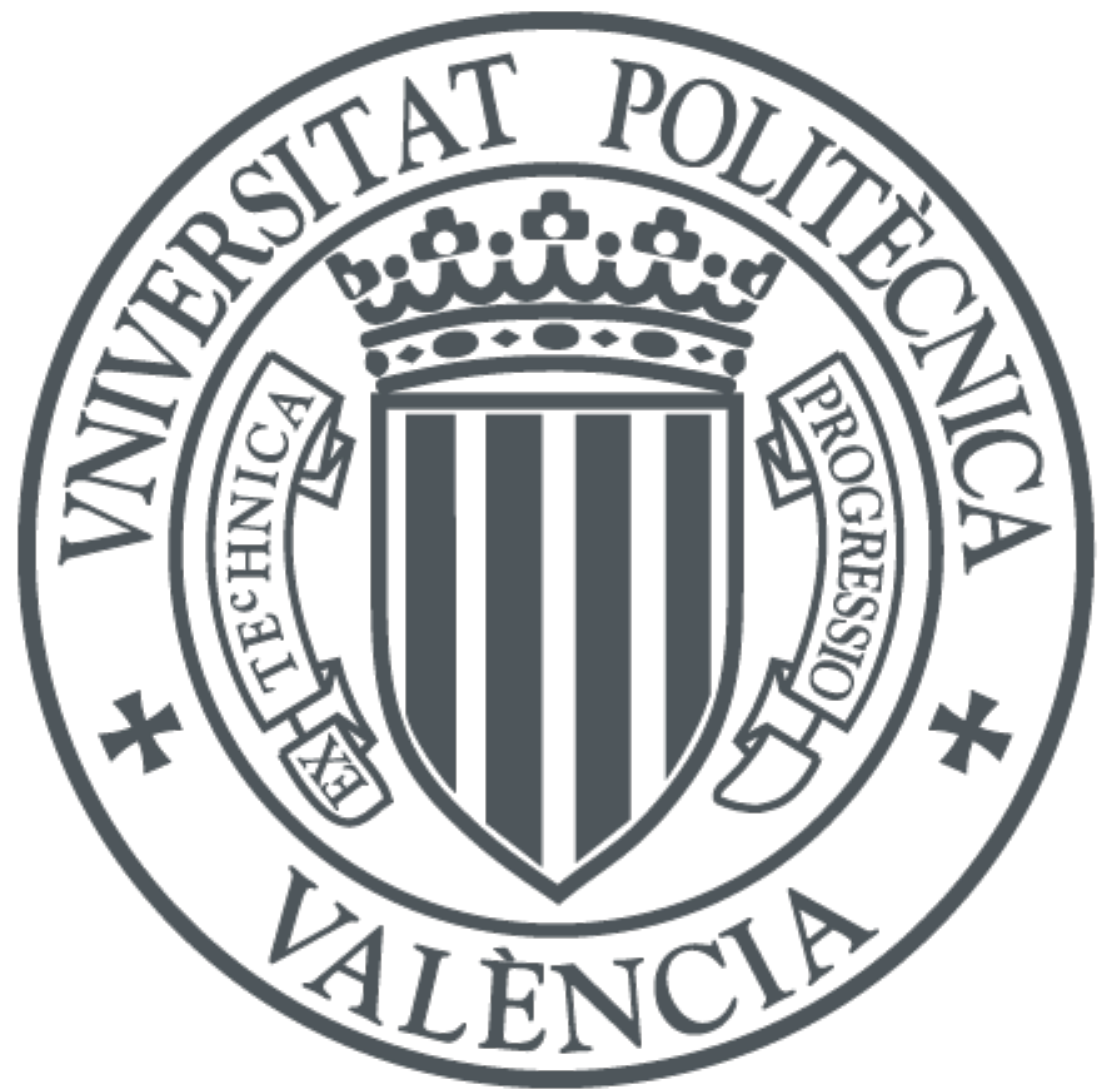

The final publication is available at

https://doi.org/10.1177/0021998317733318

Copyright SAGE Publications

Additional Information 


\title{
Composite modular floor prototype for emergency housing applications: experimental and analytical approach
}

\author{
Hassan Abdolpour ${ }^{\mathrm{a}, 1}$, Julio Garzón-Roca ${ }^{\mathrm{b}}$, Gonçalo Escusa ${ }^{\mathrm{a}}$, \\ José M. Sena-Cruz ${ }^{\mathrm{a},}$, Joaquim A.O. Barros ${ }^{\mathrm{a}}$, Isabel B. Valente ${ }^{\mathrm{a}}$ \\ ${ }^{a}$ ISISE, University of Minho, Guimarães, Portugal \\ ${ }^{\mathrm{b}}$ Department of Geotechnical and Geological Engineering, Universitat Politècnica de València, Valencia, Spain
}

\begin{abstract}
The present paper explores a new modular floor prototype to be used in emergency houses. The prototype is composed of a frame structure made of glass-fiber-reinforced polymer (GFRP) tubular pultruded profiles, a slab made of sandwich panels with a polyurethane (PU) foam core and GFRP skins, and a tailored connection system that provides integrity between assembled components. A series of experimental tests are carried out including flexural tests on a single panel, on two and three connected panels, and on the assembled floor prototype. The behaviour of the panels is analysed when they are not considered part of the GFRP framed structure, namely the failure mechanisms and the efficiency of the proposed connection system between the panels. The performance of the floor prototype to support typical load conditions of residential houses is also assessed. Additionally, an analytical model was used to deeper study the behavior of the developed sandwich panels, connection system and the modular floor prototype.
\end{abstract}

Keywords: emergency house; composite materials; GFRP pultruded profiles; sandwich panels; GFRP skins; PU foam core

\section{Introduction}

One of the major concerns after a natural disaster is settling down surviving communities in shelters or temporary houses. This issue remains difficult to manage despite decades of experience. Availability of temporary housing is crucial since it allows people to quickly restart their daily activities such as school, working and cooking ${ }^{1-3}$. Even though there are different sorts of temporary buildings made of steel, wood and plastic ${ }^{4-6}$, many of these temporary dwellings do not offer a basic level of security and protection for its

\footnotetext{
${ }^{1}$ Corresponding author. Tel.: +351-253-510-200; fax: +351-253-510-217

E-mail address: Hassan.abdolpour@gmail.com (H. Abdolpour)
} 
occupants, and/or result in very complex and expensive solutions. Nowadays, a clear trend is observed in the industrial manufacturing and prefabrication of temporary building towards. This modern method of construction leads to achive tangible benefits in terms of faster construction, improved quality and reduced wasting resource material $^{7}$.

Lightness is a key factor when proposing a material/structural system for a temporary building because, after a natural disaster, accessibility to roads is usually limited. Thus, low weight prefabricated components are very convenient for packing, shipping, unpacking and assembling ${ }^{8}$. Taking this into account, sandwich panels made mainly by GFRP pultruded profiles and sandwich panels may constitute excellent options in the field of temporary buildings. Sandwich panels and pultruded profiles are lightweight elements with very good mechanical performance, being able to be manufactured and rapidly assembled in modular sections.

Typically sandwich panels are composed of two thin and stiff outer faces separated by a thick and low density core material. These panels offer various advantages, such as high strength and stiffness to weight ratio, immunity to corrosion, and a low thermal and acoustic conductivity ${ }^{9-13}$. Likewise, pultruded GFRP profiles show a series of promising advantages, such as relatively low production costs, low maintenance, high durability, immunity to corrosion and high strength ${ }^{14-17}$. Accordingly, sandwich panels have been efficiently used in several structural applications, such as cladding ${ }^{18}$, facades ${ }^{19,20}$, roofing ${ }^{21,22}$ and walls ${ }^{23,24}$.

In the scope of this work the mechanical behaviour of a modular floor prototype, developed to be used in temporary emergency houses, is assessed. The proposed basic unit system is capable of covering an area of approximately $9 \mathrm{~m}^{2}$. Three sandwich panels, made of GFRP skins and PU foam cores, were used for configuring the enclosed floor surface, while GFRP tubular pultruded profiles formed the skeleton of the system. Elements were adequately interconnected upon assembly, constituting a floor system and providing a diaphragm behaviour ${ }^{25}$. In addition, the fitting connection system was designed for an easy and fast assembling and disassembling of the connected elements.

The prototype is analysed through a series of experimental and analytical studies. In a first stage, the flexural behaviour of a single panel, and systems formed by two and by three connected panels are experimentally assessed under serviceability limit state (SLS) and ultimate limit state (ULS) conditions. The tests with the systems of panels have also the purposes of analyzing the efficacy and contribution of the connection between panels, by studying the transference of loads from one panel to the adjacent ones. Furthermore, ultimate capacity of a single floor panel and its corresponding failure mechanism system is experimentally assessed. In a second 
stage, an experimental program is conducted to evaluate the performance of the developed basic floor unit prototype as a structure designed to support serviceability and ultimate load conditions in residential houses. Finally, analytical studies are carried out to contribute for a deeper assessment of the failure mode of sandwich panels, the influence of the ribs placed inside the panels, the efficiency of the connections, and the behaviour of the floor prototype.

\section{Prototype description}

\subsection{Concept and geometry}

The designed temporary building house was composed of a single-story building with a rectangular area of about $6.0 \times 3.0 \mathrm{~m}^{2}$, formed by connecting two blocks of about $3.0 \times 3.0 \mathrm{~m}^{2}$ and a height of about $3.0 \mathrm{~m}$. Fig. 1 shows a plan and three lateral views, as well as a photo of the built prototype. This temporary building house was developed in the scope of the R\&D project named ClickHouse.

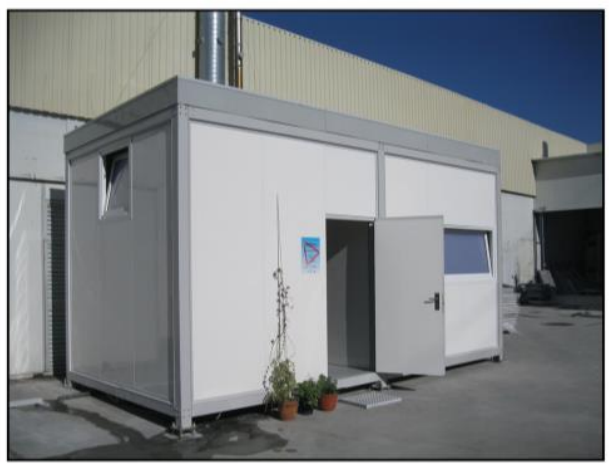

(a)

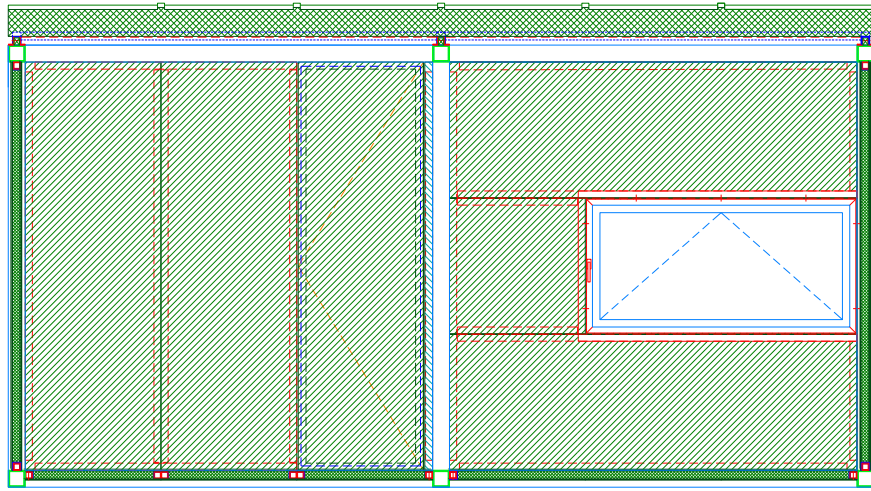

(c)

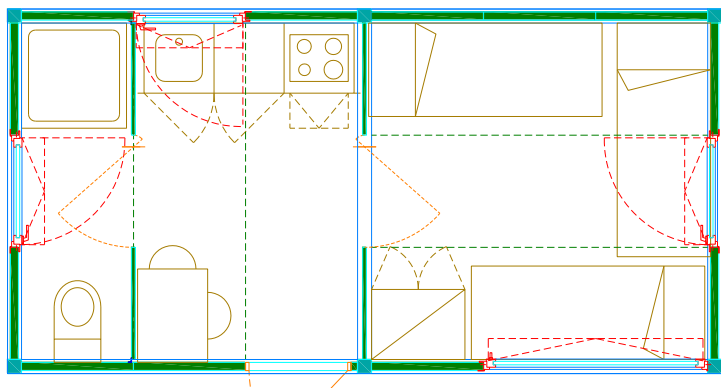

(b)

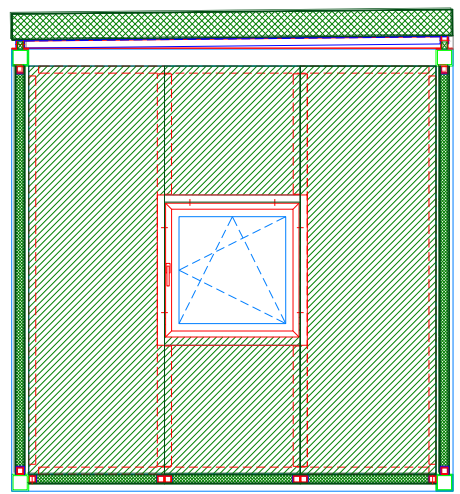

(d)

Fig. 1. Modular system schematic view: (a) Prototype built; (b) Plan view; (c) south view; (d) east view. 
The floor module of the building is depicted in Fig. 2 and was composed of two main components: (i) a frame structure formed by tubular GFRP pultruded profiles with a cross section of $120 \times 120 \mathrm{~mm}^{2}$ and a wall thickness of $8 \mathrm{~mm}$ (Fig. 2a), and (ii) the pavement constituted by three sandwich panels formed by two outer GFRP skins of $5 \mathrm{~mm}$ thickness and a core of PU foam (Fig. 2b). For the sake of decreasing segment's variation in the manufacturing process, the same profile was used in both beams and columns of the frame.

The panels presented an overall thickness of $70 \mathrm{~mm}$, a width of $1000 \mathrm{~mm}$ and a length of $3000 \mathrm{~mm}$. A U-shape GFRP pultruded profile with a cross section of $60 \times 55 \mathrm{~mm}^{2}$ and a wall thickness of $5 \mathrm{~mm}(\mathrm{U} 60 \times 55 \times 5)$ was adhesively bonded to the GFRP skins and the PU foam core during the manufacturing process, on the outer side of each panel, enabling the connection of each panel to the other elements of the prototype, such as beams and other panels (see Fig. 2 c). For increasing the flexural stiffness of the panel, two additional U60 $\times 55 \times 5$ profiles were installed in the interior of each panel (see Fig. 2c). PU foam blocks with a thickness of $60 \mathrm{~mm}$ and nominal density of $48 \mathrm{~kg} / \mathrm{m}^{3}$ were used to form the sandwich panel core, providing the required thermal isolation. These blocks were bonded to the GFRP skins with a polyester resin.

GFRP material was selected for the skins over traditional materials, such as steel ${ }^{26,27}$ or concrete, mainly due to its impunity to corrosion and higher strength/lightness ratio. The GFRP skins were produced with the handlayup technique, using dry glass fibres impregnated with an isophthalic polyester adhesive. Multiple plies of glass fabrics were used in the process, comprising two different types of mat: chopped strand mat (CSM) and bidirectional woven fabric mats (BWFM). Each skin had five layers disposed symmetrically towards its middle surface (CSM-300 gr/m², CSM-450 gr/m², CSM-450 gr/m² + BWFM-500 gr/m², CSM-450 gr/m², CSM-300 $\mathrm{gr} / \mathrm{m}^{2}$ ) impregnated with adhesive. The weight of the sandwich panel was around $70 \mathrm{~kg}$, which facilitates its transportation and on-site installation.

The connections were designed for an easy and fast assembling / disassembling of the prototype, and assure continuity as much as possible between connected elements in order to mobilize efficiently their strength capacity (see Details 1 to 3 of Fig. 2). For beam-panel connections, the aforementioned U-shape GFRP profiles placed on the edges of the sandwich panels were attached to a GFRP squared tubular profile of $50 \mathrm{~mm}$ edge and $5 \mathrm{~mm}$ of thickness that was mechanically and adhesively bonded to the GFRP beam (see Detail 2 in Fig. 2). Finally, for panel to panel connection, a similar approach as that followed for beam-panel connection was used, by attaching the U-shape GFRP profiles to two GFRP squared tubular profiles (also of $50 \mathrm{~mm}$ edge and $5 \mathrm{~mm}$ of 
thickness) that were mechanically and adhesively connected together in order to form a rectangular tubular of $100 \mathrm{~mm} \times 50 \mathrm{~mm}$ (see Detail 3 in Fig. 2).

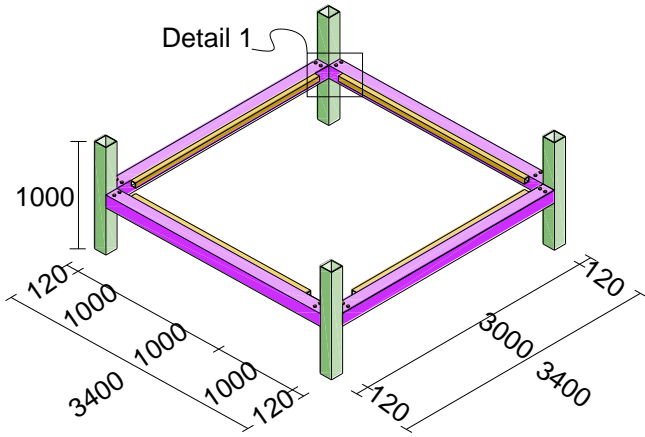

(a)

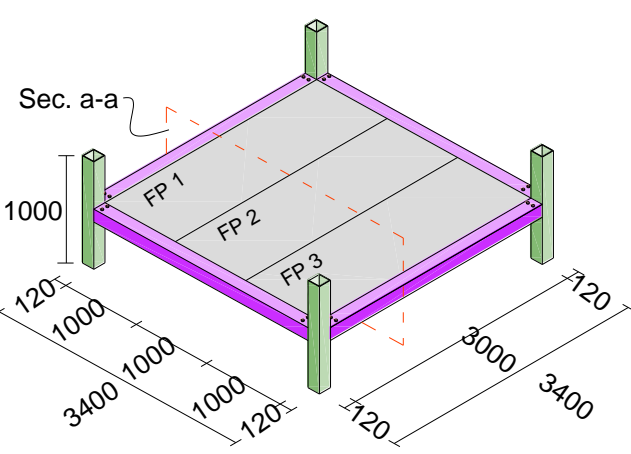

(b)

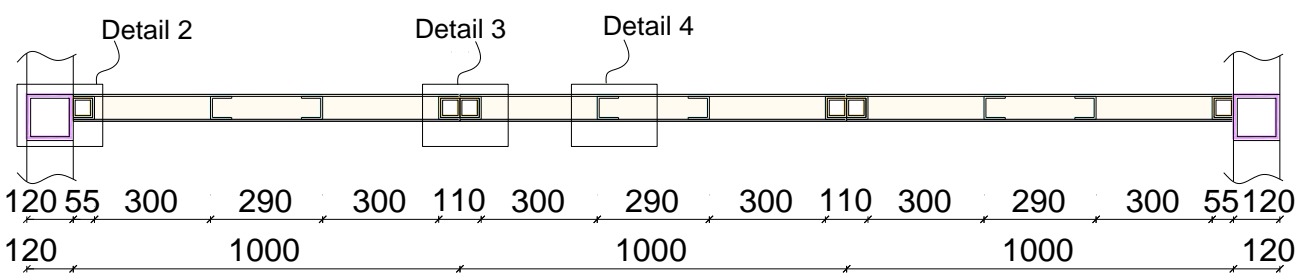

(c)

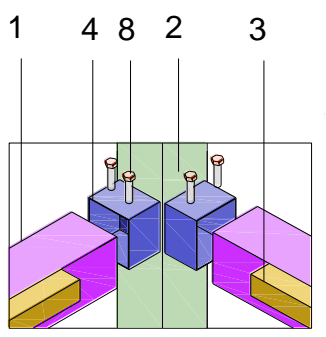

Detail 1

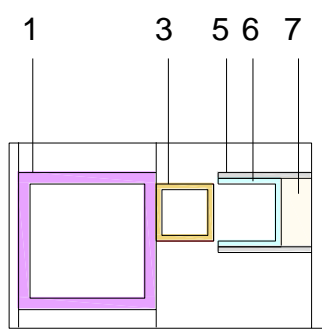

Detail 2

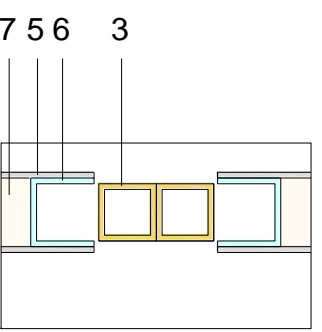

Detail 3

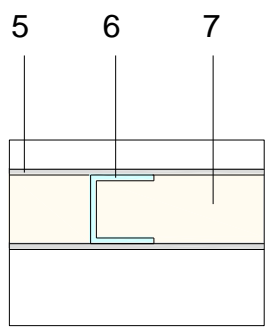

Detail 4

Legend: (1) GFRP beam; (2) GFRP column; (3) GFRP square profile; (4) steel profile; (5) GFRP skin; (6) GFRP U profile; (7) PU foam core; (8) steel bolt

Fig. 2. Schematic presentation of the floor prototype: (a) frame structure; (b) frame structure and sandwich floor panels; (c) cross section a-a (all units in $\mathrm{mm}$ ).

\subsection{Assembly process}

The floor prototype was developed for disaster areas where special tools and equipment, as well as experimented workers, are scarce. Consequently, these issues were also considered in the design process of the prototype. 
Fig. 3 shows a general view of the process needed to assemble the floor of the developed prototype. The process starts by placing the four columns in their positions (note that for the floor test proposed in this paper, short columns with approximately $1 / 3$ of the real height were used), and then connecting three of them by beams (Figs. 3a and 3b). Afterwards, the three sandwich panels were installed. Panels were handled and mounted along the beam-panel connections (Fig. 3c), placing the panel to panel connectors after positioning the first and the second panels (Fig. 3d). After assembling the third panel, the last beam of the frame was installed and connected (Fig. 3e) - fixing ropes were used along the process for facilitating the adjustment of the panels. Fig. 3f shows the floor prototype after has been assembled, which required less than 2 hours and three people without any special equipment and skills.
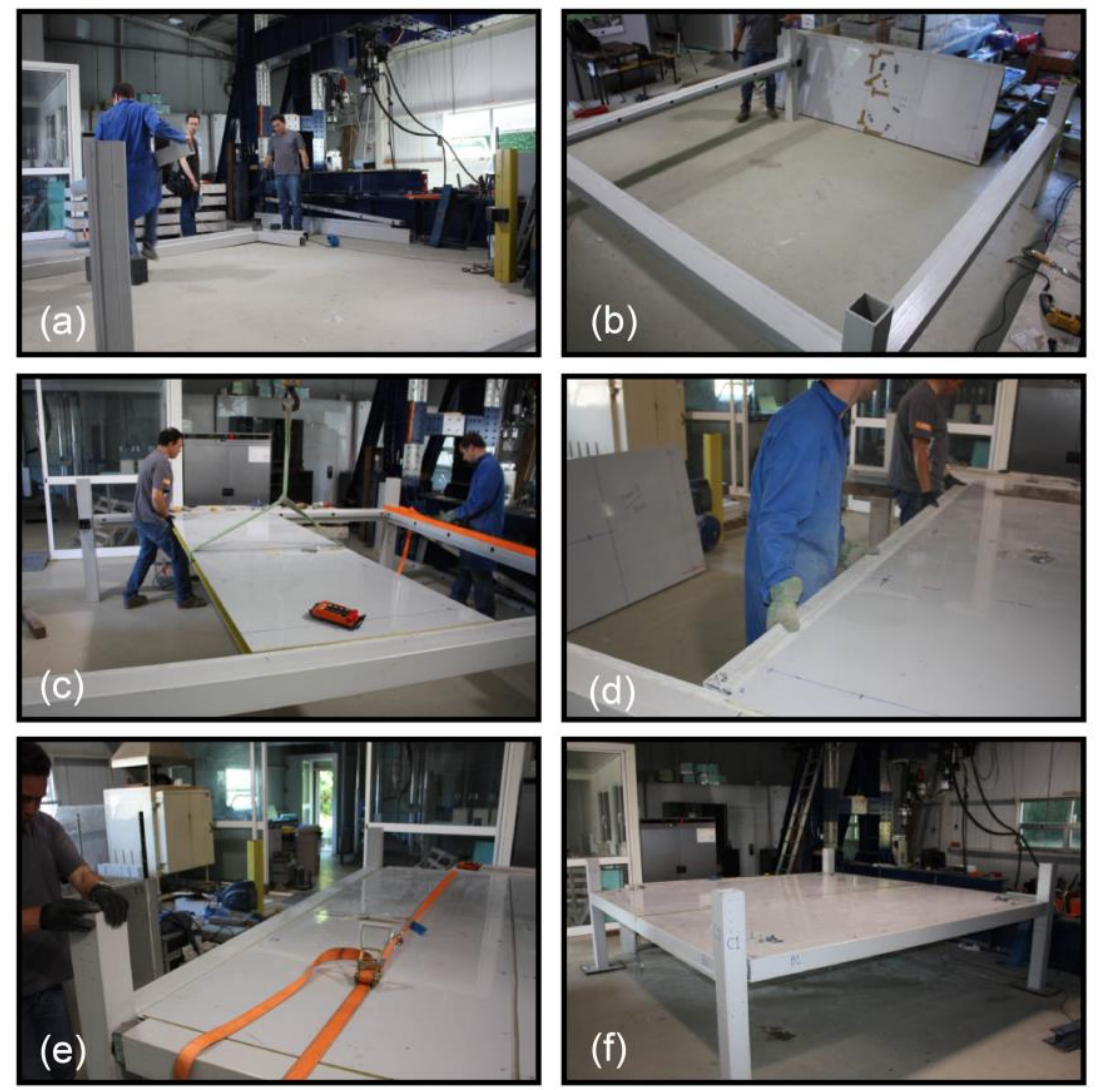

Fig. 3. Stages of the assembling process: (a) placing columns; (b) connecting beams to the columns;

(c) mounting panels along beam-panel connection; (d) placing panel-panel connector; (e) installing the last beam; (f) final prototype.

\section{Experimental programme}

The following subsections provide details on the experimental programme conducted in terms of material characterization, test specimen, setup and procedures. All tests were carried out in the Laboratory of the Structural Division of the Civil Engineering Department at University of Minho, Portugal (LEST). 


\subsection{Material characterization}

Both GFRP profiles and sandwich panel GFRP skins were characterized by performing tensile tests according to ASTM D3039 recommendations ${ }^{28}$. Five tensile specimens with dimensions of $250 \times 25 \times 5 \mathrm{~mm}^{3}$ were extracted from the profiles, and from the sandwich panel skins in both longitudinal and transverse directions. Tensile tests were conducted in a universal testing machine, with a grip distance of $150 \mathrm{~mm}$, and monotonically loaded up to failure, with a head displacement rate of $2 \mathrm{~mm} / \mathrm{min}$ (Fig. 4a).

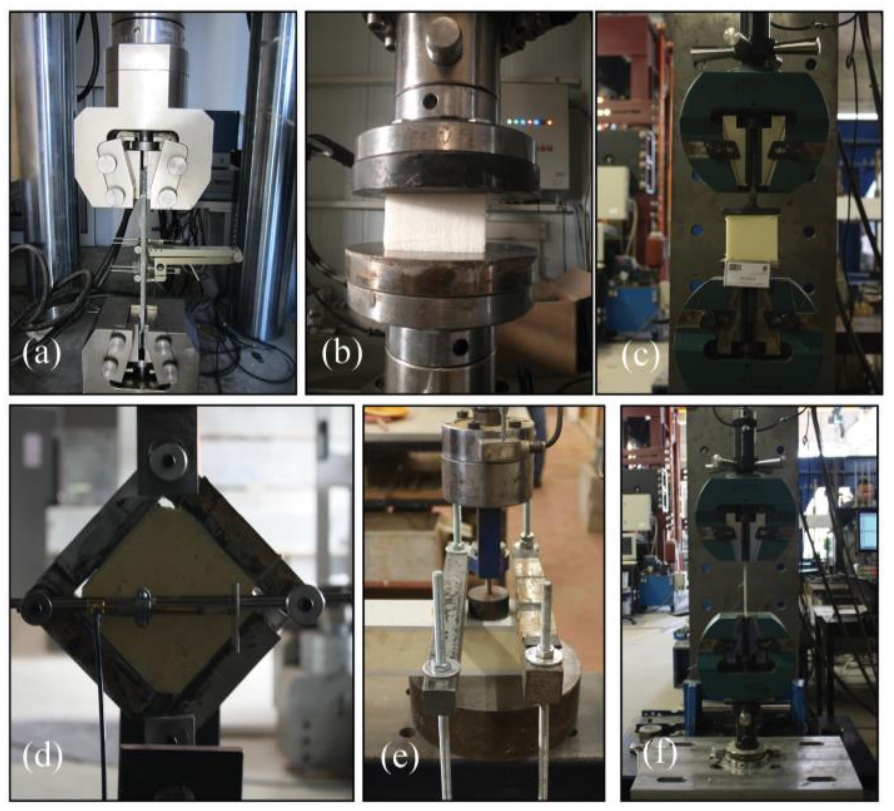

Fig. 4. Material characterization test setups: (a) GFRP tensile test; (b) PU compressive test; (c) PU tensile test; (d) PU shear test; (e) pull off test; (f) epoxy tensile test.

Mechanical properties of the PU foam core were evaluated under compression, tension and shear tests. Flatwise compression properties of the PU foam were determined according to the ASTM C365-03 recommendations ${ }^{29}$, by testing five prism-shape coupons of $70 \times 70 \times 50 \mathrm{~mm}^{3}$ (Fig. 4b). Tensile properties of the PU foam were evaluated according to ASTM C297/C 297 M-04 prescriptions ${ }^{30}$, by testing five coupons of $70 \times 70 \times 50 \mathrm{~mm}^{3}$ adhesively bonded to the flange of steel T-section (Fig. 4c). For the shear testing, five cubic specimens with a dimension of $120 \times 120 \times 120 \mathrm{~mm}^{3}$ were prepared. The specimens were bonded to four metallic plates and mounted in the universal testing machine where a tension load was applied along one side of the setup (Fig. 4d). The applied load was transferred into the plates that were encasing the specimen. Comprehensive information about this test can be found elsewhere ${ }^{31}$.

Tensile bond strength of the adhesive joint between GFRP skin and PU foam core was measured by pull-off tests based on ASTM 1583-04 recommendations ${ }^{32}$. Five cores were drilled on GFRP skins with a diameter of 
$50 \mathrm{~mm}$ and a core depth of about $10 \mathrm{~mm}$. Aluminium disks were adhesively glued to the GFRP skin. Tensile force was applied to the disks with a head displacement rate of $0.2 \mathrm{~mm} / \mathrm{min}$ (Fig. 4c).

Finally, the tensile behaviour of the polyester resin (adhesive material used to glue GFRP skin to PU foam core) was assessed by performing direct tensile tests, according to ASTM D638 prescriptions ${ }^{33}$. The samples were cast in dog-bone mould shapes and cured following the standard recommendations. Specimens were tested in a universal testing machine at a displacement rate of $2 \mathrm{~mm} / \mathrm{min}$ (Fig. 4f).

\subsection{Single sandwich floor panel: tests under uniformly distributed loading}

Four full-scale floor sandwich panels (hereafter designated by FP1 to FP4) were tested under a uniform load to evaluate their structural performance as a single panel. Following the UNHCR recommendation ${ }^{34}$ for an emergency house, a uniform load of $1.6 \mathrm{kN} / \mathrm{m}^{2}$ was selected to be as the load value in SLS. That load was increased 1.5 times to evaluate their response under ULS conditions, as traditionally defined in the Eurocodes.

The panels were tested with a clear span of $2700 \mathrm{~mm}$, and supports were materialized by placing a steel roller with a diameter of $50 \mathrm{~mm}$ under both panel ends. Both supports allowed free rotation and one of them also permitted longitudinal sliding (roller support), while the other was fixed in the longitudinal direction (pinned support). Load was manually applied by using cement bags of $20 \mathrm{~kg}$ each. In a first step (SLS loading configuration) 16 cement bags were disposed in two layers, representing a uniform distributed load of $1.6 \mathrm{kN} / \mathrm{m}^{2}$. In a second step eight extra bags were added to attain a loading level corresponding to ULS conditions. Loading operations were performed as fast as possible to avoid any potential creep effect. The cement bags were distributed as uniformly as possible on the panels, but gaps between bags were assured to avoid any arch effect.

Vertical displacement was measured by means of a Linear Variable Differential Transformers (LVDT) placed at the intersection of the specimen's midspan section with its longitudinal axis. The panels were also instrumented in the tension skin (bottom skin) with a strain gauge bonded at a distance of $10 \mathrm{~mm}$ from the centre of the panel to avoid any interference with the LVDT.

\subsection{Single floor sandwich panel: tests up to failure}

The static behaviour of one-way full scale sandwich panel up to its failure was investigated by executing a fourpoint bending test according to the ASTM C393 recommendations ${ }^{35}$. The panel was tested with a shear span of 
$850 \mathrm{~mm}$, and supports were materialized as already described for the single panels submitted to a uniformly distributed load.

Hydraulic jack was used to apply a monotonic load up to the failure of the specimen. The load was transferred to the panel by means of a longitudinal spreader HEB 200 with a length of $2000 \mathrm{~mm}$, and two IPE 100 profiles with steel rollers of $20 \mathrm{~mm}$ of diameter welded at their bottom flange. A load cell of $300 \mathrm{kN}$ (with a precision of $0.05 \%$ ) was used to register the load applied. Rubber pads were placed between the panel and the steel rollers to avoid any indentation failure ${ }^{36-39}$. Fig. 5a shows the test setup configuration.

Vertical displacements were recorded by five LVDTs with a stroke ranging from $25 \mathrm{~mm}$ to $50 \mathrm{~mm}$, placed under loaded sections (D4 and D5) and at mid-span (D1 to D3). Moreover, six strain gauges were bonded on the bottom skin (S1 to S3) and on the top skin (S4 to S6) at the midspan section of the specimen (see Fig. 5b).

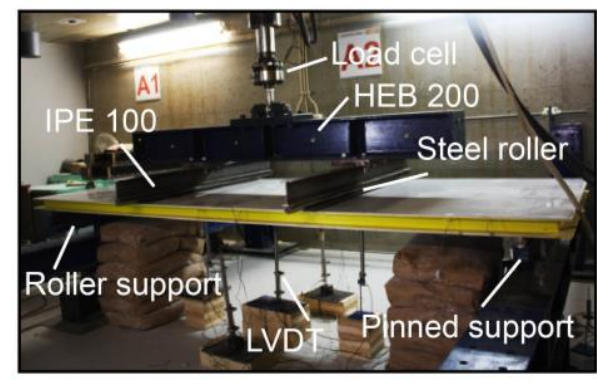

(a)

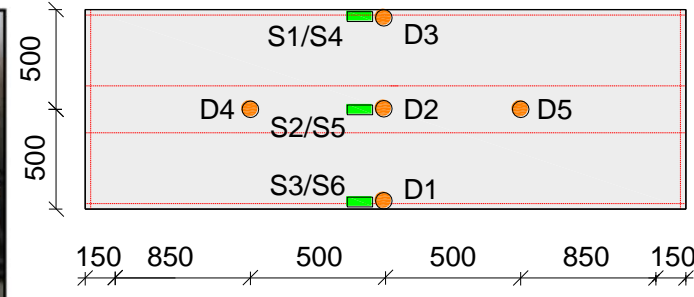

S: strain gauge and D: LVDT

S1-S3 on bottom skin and S4-S6 on top skin

(b)

Fig. 5. Single panel four-point bending test: (a) test setup; (b) instrumentation (all units in mm).

\subsection{Flexural response of connected sandwich panels}

After have been submitted to uniformly distributed load, the three floor panels (FP) described in Section 3.2 (FP1 to FP3) were also tested (Fig. 6a) in a two-by-two connection configuration (FP1 with FP2 and FP2 with FP3). Each pair was connected together by the GFRP tubular rectangular profiles of $100 \times 50 \times 5 \mathrm{~mm}^{3} \mathrm{cross}$ section previously mentioned, in order to resemble the arrangement of the floor prototype (see Fig. 2c). A test with the three panels (Fig. 6b) connected together (FP1, FP2 and FP3) was also carried out. All these tests were undertaken under a four-point bending configuration with a shear span, a flexural span and a clear span of $850 \mathrm{~mm}, 1000 \mathrm{~mm}$ and $2700 \mathrm{~mm}$, respectively, and according to ASTM C393 recommendations ${ }^{35}$. The support conditions were similar to those adopted previously in the single panel tests. 

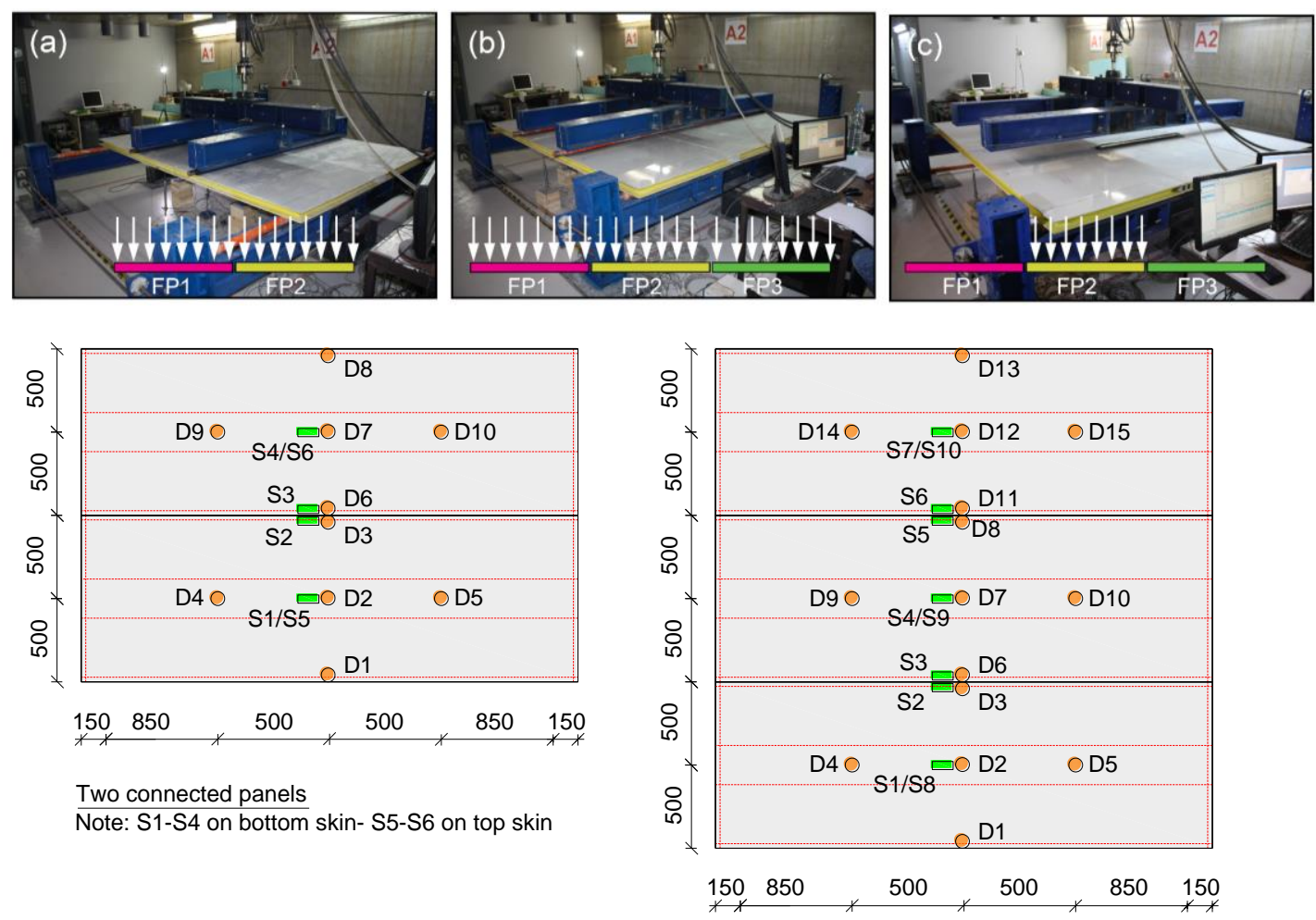

Three connected panels

Note: S1-S7 on bottom skin- S8-S10 on top skin

(d)

(e)

Fig. 6. Connected panel flexural tests: (a) two connected panels; (b) three connected panels; (c) connection study; (d) instrumentation for two connected panels; (e) instrumentation for three connected panels (all units in $\mathrm{mm})$.

The load was transferred to the panels by means of a frame formed by a $2000 \mathrm{~mm}$ long metallic HEB 200 profile, to which was attached (welded) two transverse HEB 200 profiles with a length equal to the width of the connected panels (i.e. $2000 \mathrm{~mm}$ for the case of two panels and $3000 \mathrm{~mm}$ for the case of three panels). Two cylinder steel bars of $50 \mathrm{~mm}$ diameter were placed between the panel and the load transfer frame in order to apply a line load. A monotonically increase load was applied by a hydraulic jack on the panels until reaching a magnitude of $10.3 \mathrm{kN}$ and $15.4 \mathrm{kN}$ for the case of two and three connected panels, respectively. These load levels correspond, in terms of load (maximum bending moment), to an equivalent uniform load for ULS $\left(2.4 \mathrm{kN} / \mathrm{m}^{2}\right)$ in a four-point bending test configuration. A load cell of $300 \mathrm{kN}$ with a precision of $0.05 \%$ was used to measure the load applied. 
To assess the effectiveness of the connection in distributing the load amongst the connected panels, an additional test with three connected panels was conducted by applying the load only on the central panel (see Fig. 6c). This test configuration followed exactly the setup previously indicated, but in this case, the length of the steel cylinder placed under the HEB profiles was only $1000 \mathrm{~mm}$, therefore the load is exclusively applied on the central panel.

The instrumentation used for monitoring these tests is depicted in Figs. 6 ( $\mathrm{d}$ and e). Ten and fifteen LVDTs (with a stroke ranging from $25 \mathrm{~mm}$ to $50 \mathrm{~mm}$ ) were used in the two and three connected panels, respectively, for measuring the vertical deflection of the panels in their loaded and mid-span sections. Strain gauges positioned on both skins (top and bottom), at the midspan of the specimen were used to measure the strains developed in GFRP skins.

\subsection{Loading test on the modular prototype}

After the prototype has been built by assembling its components according to the description in Section 2.2, its structural behaviour was evaluated under a uniform load of $1.6 \mathrm{kN} / \mathrm{m}^{2}$ in SLS and $2.4 \mathrm{kN} / \mathrm{m}^{2}$ in ULS. These values, as already indicated, correspond to UNHCR recommendations for temporary buildings. The loading arrangement was materialized by using a swimming pool of circular area and $6.25 \mathrm{~m}^{2}$ as illustrated in Fig. 7a.

The monitoring system adopted for this test is displayed in Fig. 7b. Eleven LVDTs (D1 to D11) with a stroke ranging from $25 \mathrm{~mm}$ to $50 \mathrm{~mm}$ were placed at the bottom of the prototype to measure vertical deflection, while 15 strain gauges ( $\mathrm{S} 1$ to $\mathrm{S} 15$ ) were positioned on the bottom surface of the beams and panels to register the strains during the loading process.

\section{Results and analysis}

\subsection{Material characterization}

Table 1 summarizes the results of the material characterization tests conducted on the different components of the floor prototype, listing the values obtained for the maximum tensile stress in the longitudinal $\left(\sigma_{\max , L}\right)$ and transverse $\left(\sigma_{\max , T}\right)$ directions, elastic modulus in the longitudinal $\left(E_{L}\right)$ and transverse $\left(E_{T}\right)$ directions for both the GFRP profiles and skin. The maximum compression, tension and shear stress for the PU foam, and its longitudinal $(E)$ and transverse $(G)$ elasticity modulus in compression are also provided in this table. 
The specimens of GFRP profiles and skins presented tensile linear-elastic behaviour up to failure, which took place in a brittle manner in their middle part, having the rupture surface progressed perpendicularly to the specimen axis.

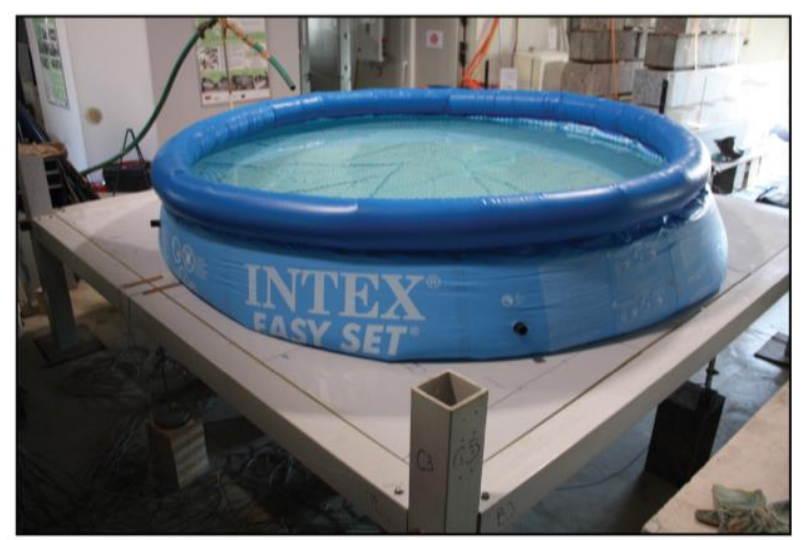

(a)

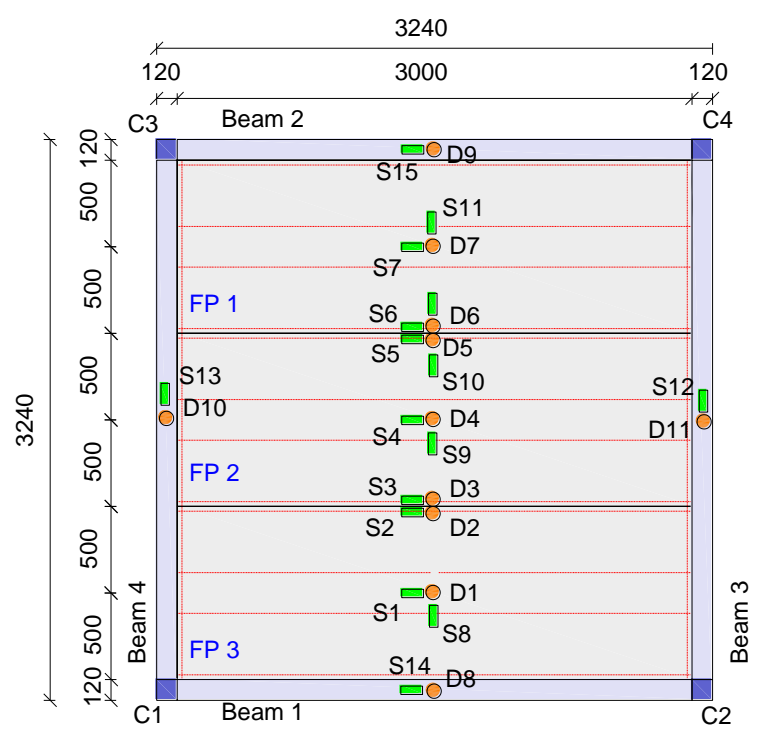

(b)

Fig. 7. Prototype test setup: (a) loading procedure; (b) monitoring system (all units in mm).

The PU foam under compression developed a linear elastic stress-strain response, followed by a plastic plateau with nearly constant stress, and a final strain-hardening stage at relatively large strain level due to the increase of stiffness caused by the large experienced deformation, which is a typical behaviour for this type of foams ${ }^{40,41}$. The response of the PU foam in shear was linear-elastic until failure, with the formation of failure surfaces at an angle of nearly $45^{\circ}$. The PU foam coupons submitted to tension also presented a linear elastic behaviour up to failure, with a slight strain hardening in the last loading stage. 
In the pull-off tests, a tensile strength of $0.5 \mathrm{MPa}(\mathrm{CoV}=18.7 \%)$ was obtained. The failure has occurred in the PU foam core. No failure was detected in the interface between GFRP and the PU foam core. Since the ultimate tensile strength of the PU foam core was quite close to the tensile strength obtained in the pull-off tests $(0.5 \mathrm{MPa})$, it is confirmed the rupture was caused by the attainment of the tensile capacity of PU foam.

Table 1 Materials used in sandwich wall panels (mean values).

\begin{tabular}{lcccc}
\hline GFRP & $\sigma_{\max , L}(\mathrm{MPa})$ & $\sigma_{\max , T}(\mathrm{MPa})$ & $E_{L}(\mathrm{MPa})$ & $E_{T}(\mathrm{MPa})$ \\
\hline GFRP profiles & $327.1(8.6 \%)$ & $230.1(7.6 \%)$ & $32.0(6.8 \%)$ & $16.1(8.9 \%)$ \\
GFRP skin & $117.0(10.4 \%)$ & $1 \mid 16.9(14.7 \%)$ & $9.6(7.4 \%)$ & $10.3(8.0 \%)$ \\
\hline Foam & $\sigma_{\max }(\mathrm{MPa})$ & $E(\mathrm{MPa})$ & $G(\mathrm{MPa})$ & \\
\cline { 2 - 4 } Compression test & $0.30(10.0 \%)$ & $6.3(9.0 \%)$ & -- & \\
Tensile test & $0.49(8.9 \%)$ & -- & -- & \\
Shear test & $0.15(10.2 \%)$ & -- & $3.2(12.1 \%)$ & \\
\hline
\end{tabular}

Notes: $L$ : longitudinal direction; $T$ : transverse direction; the values between parentheses are the corresponding coefficients of variation.

\subsection{Single sandwich floor panel: tests under uniformly distributed loading}

The registered midspan deflections and midspan strains for tested panels FP1-FP4 under uniformly distributed load are shown in Figs. 8 ( $\mathrm{a}$ and b), respectively. The application of the load in two steps, corresponding to SLS $\left(1.6 \mathrm{kN} / \mathrm{m}^{2}\right)$ and ULS $\left(2.4 \mathrm{kN} / \mathrm{m}^{2}\right)$ load conditions is fully recognizable in the graphs by the abrupt increase of midspan deflection (and strain) after the stabilization stage at the end of the SLS loading process (SLS_L). As can be seen, a full recovery of the deflections and strains took place after the total unloading phase, which evidences that for the considered load levels the panels have presented an elastic behaviour. Moreover, Fig. 8 shows that, the values for both deflections and strains registered were very similar in the four tested panels, revealing a manufacturing process of high repeatability.

The Italian standard CNR can be used to verify the performance of sandwich panels under SLS ${ }^{42}$. According to this standard, the maximum long-term deflection registered for the quasi-permanent loading, $\delta_{\text {Quasi }}$, (equal to $30 \%$ of the service load) should be less than $L / 250$. The $\delta_{\text {Quasi }}$ considering creep effects is determined from the following equation:

$\delta_{\text {Quasi }}=\alpha \times \delta_{S L S} \times \gamma_{\text {Creep }}$ 
where $\delta_{S L S}$ is the deflection in SLS loading conditions, $\alpha$ is the proportion of quasi-permanent loading in respect to the SLS loading (i.e. 30\%), and $\gamma_{\text {Creep }}$ is the estimated coefficient due to creep effects. Based on creep tests previously carried out by the authors on similar panels ${ }^{43}$, a value of 2.52 was obtained for $\gamma_{\text {Creep }}$ (this value takes into account a service life of 5 years). Considering the average experimental deflection value obtained under SLS (7.5 mm), Eq. (1) gives a value of $5.7 \mathrm{~mm}$ for the maximum deflection expected to be registered in long-term, which is lower than the limit recommended by CNR code ${ }^{42}(\mathrm{~L} / 250=2700 / 250=10.8 \mathrm{~mm})$, and therefore the panels fulfilled the deflection serviceability requirements.

Under ULS loading conditions the average of the maximum bottom tensile strains recorded at midspan was 491 microstrains $(\mu \varepsilon)$, which is a value significantly lower than the ultimate tensile strain of GFRP skins obtained experimentally $(12188 \mu \varepsilon)$.

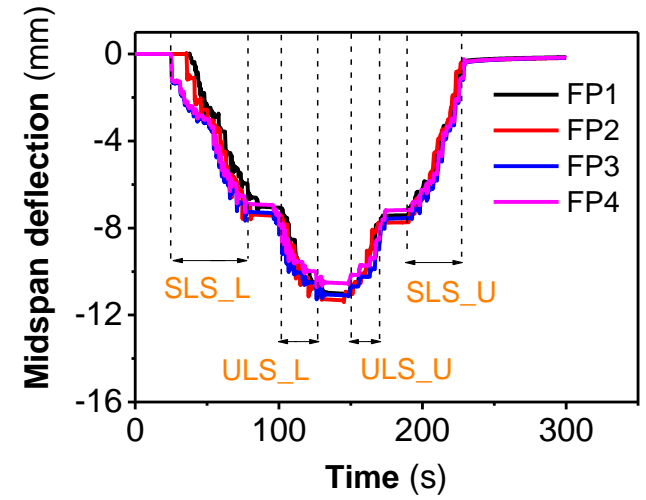

(a)

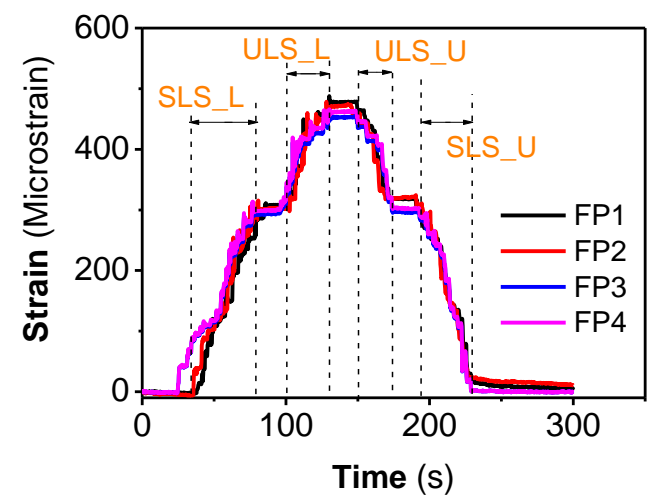

(b)

Fig. 8. Results of single sandwich floor panel tested under uniformly distributed load: (a) midspan deflection (D2) versus time; (b) strain (S2) versus time.

\subsection{Single sandwich floor panel: tests up to failure}

The load-deflection relationship of the single panel tested up to failure under a four-point bending configuration is depicted in Fig. 9a. The panel failed at a maximum load of $28.5 \mathrm{kN}$, at which the midspan deflection was $61.0 \mathrm{~mm}$. The panel exhibited a linear behaviour up to failure, which was also attested by the strain gauges measurements plotted in Fig. 9b. The maximum tensile strain measured at midspan in both bottom and top skins was around 2600 microstrains. 


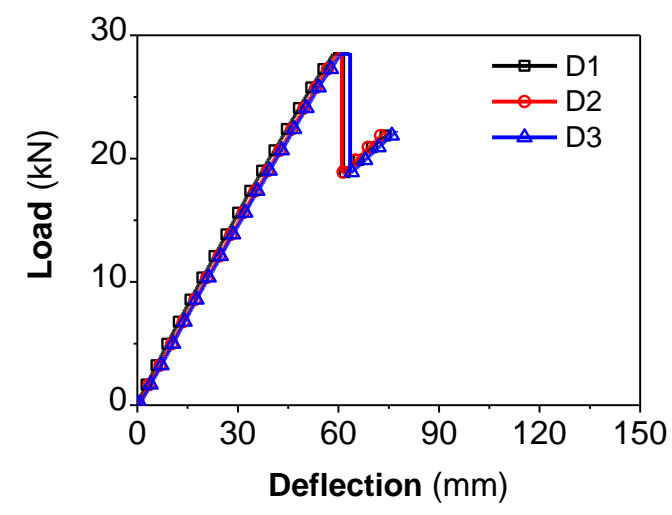

(a)

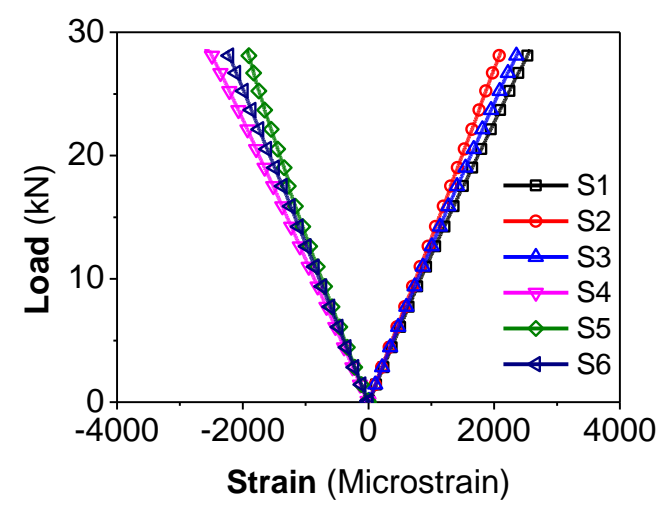

(b)

Fig. 9. Single panel tested up to its failure: (a) load versus deflection; (b) load versus strain.

Fig. 10 depicts the failure mode evolution observed on the tested panel at different loading stages. Localized debonding between GFRP compression skin (top skin) and PU foam core was the predominant failure mode of the panel. This failure occurred in the region of pure bending moment, between the two lines of loading, and was caused by a very high out-ward tensile stress between skin and core, as a result of attaining the maximum PU tensile stress ${ }^{44}$.

(a)

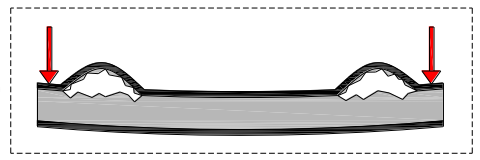

(b)

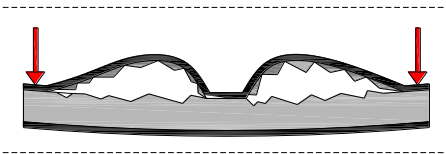

(c)

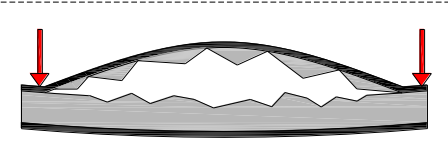

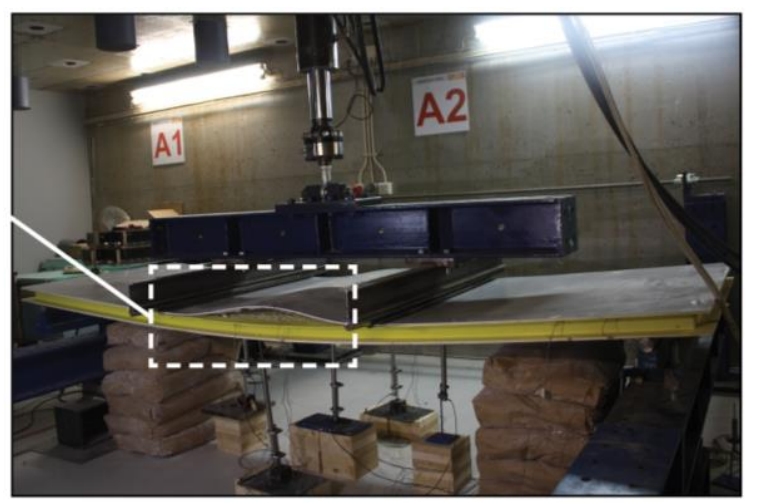

Fig. 10. Single panel tested up to its failure: (a and b) failure mode evolutions; (c) final failure mode

This phenomenon, known as local instability or wrinkling failure mode of a sandwich panel, leads to a sudden outward buckling of the GFRP skin in the compression side where the buckling wavelength is short. The initiation of wrinkling failure mode is schematically shown in Fig. 10a. It was experimentally observed that, at the beginning, the length of the debonded part was equal to the PU thickness. This observation confirmed previous information mentioned by other authors about the debonded length, referring that it could be equal to 
the PU thickness ${ }^{45-47}$. Thereafter, the debonded part propagated to the centre of the panel (Fig. 10b), and finally the sandwich panel presented an overall instability (Fig. 10c).

A failure load of $28.5 \mathrm{kN}$ was reached in the tested panel, which is much higher than the ULS load (5.1 kN). These load levels correspond, in terms of load (maximum bending moment), to an equivalent uniform load for ULS $\left(2.4 \mathrm{kN} / \mathrm{m}^{2}\right)$ in a four-point bending test configuration. This result is totally in accordance with the behavior of typical sandwich panels 19,41 , which are commonly designed for mainly fulfilling service loads, being their failing state usually far from the theoretical ultimate state.

\subsection{Flexural response of connected sandwich panels}

The load versus midspan deflection in two and three connected floor sandwich panels is depicted in Fig. 11a, while the load versus strains measured on the bottom skin is depicted in Fig. 11b. In the system formed by two connected panels (FP1-FP2 and FP2-FP3), the plotted midspan deflection and strain were computed as the average deflection/strain of the D2, D7/S1, S4 (see Fig. 6d) placed at the center of each panel. In the system formed by three connected panels, the plotted midspan deflection and strain directly corresponds to the measured deflection/strain of the D7/S4 (see Fig. 6e) placed at the center of the middle panel. The midspan deflection measured for the considered loads level was $10.6 \mathrm{~mm}$ and $10.4 \mathrm{~mm}$ for two and three connected panels, respectively, being the corresponding maximum load $10.3 \mathrm{kN}$ and $15.4 \mathrm{kN}$, respectively.

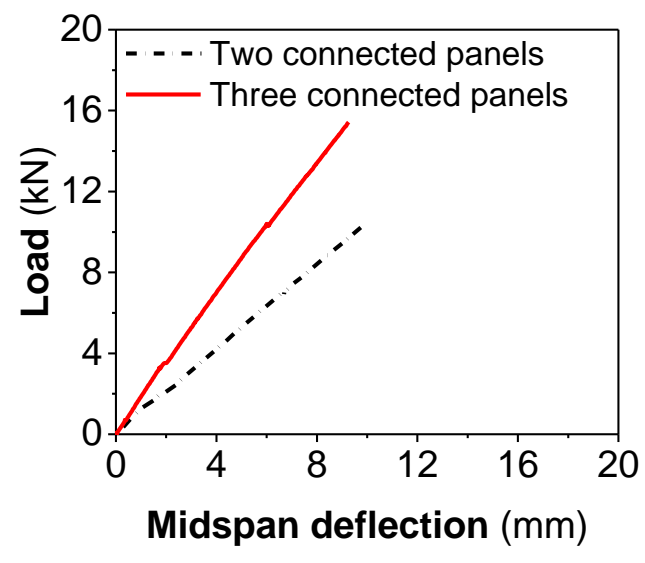

(a)

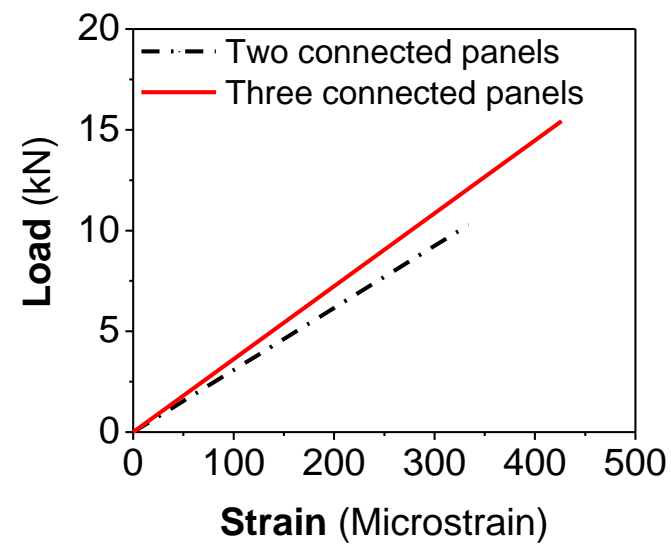

(b)

Fig. 11. Flexural behaviour of connected panels: (a) load versus midspan deflection; (b) load versus strain.

Figs. $12(\mathrm{a}$ and $\mathrm{b})$ present the deflection along the transverse direction of the midspan section of the systems formed by two and three connected panels. As can be observed, deflection at center of the connected panels was smaller than other points, having the highest deflection been measured in the free edges of the system formed by the connected panels. In the case of two connected panels, this fact can be justified by the presence of the 
connection profile at the middle of the panels, which considerably increases the stiffness of this zone. Similarly, in the case of three connected panels, the connection profiles used for joining the panels are internal stiffeners, leading the middle panel has less deflection.

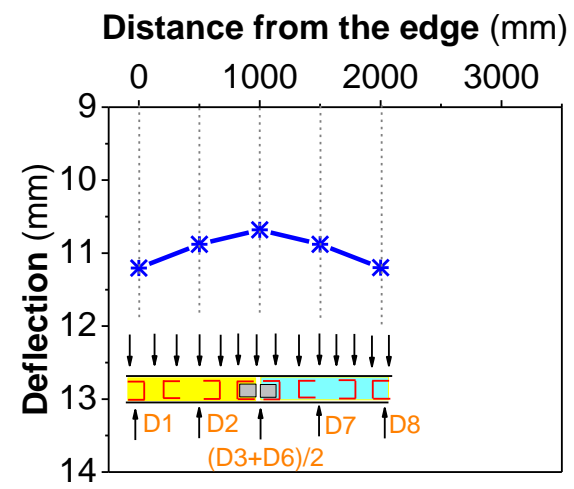

(a)

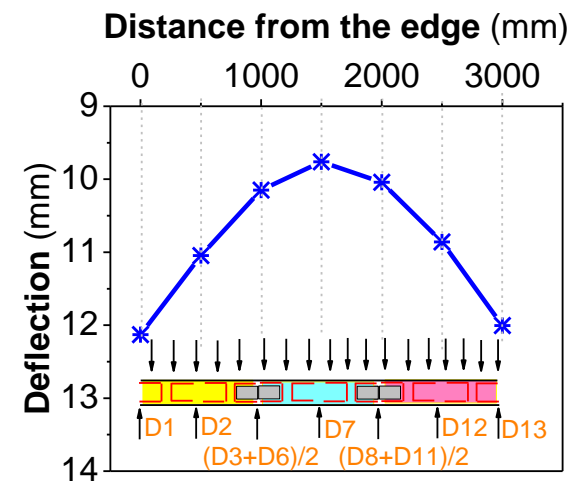

(b)

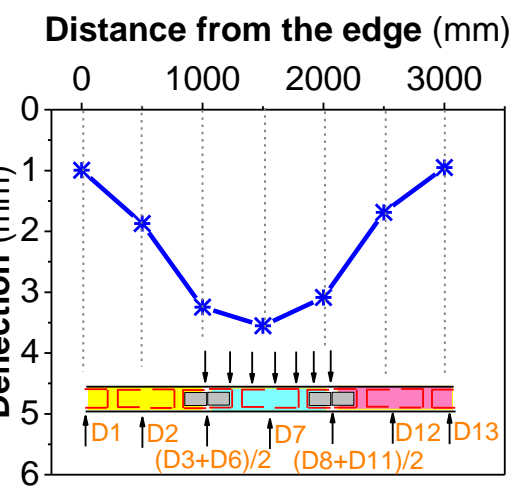

(c)

Fig. 12. Measured deflection in connected panels: (a) two panels; (b) three panels; (c) three panels with load only in the middle panel.

The effectivity of using the proposed connection system for distributing flexural loads is well demonstrated in Fig. 12c, which shows the deflection along the transverse direction of the midspan section of the systems formed 
by the three connected panels when only the central panel is loaded (see Fig. 6c). The obtained results reveal that, as expected, the highest deflection occurred in the central panel since it was the loaded one. However, the lateral panels have also deflected significantly, even their free edge, which evidences that the proposed connection system has the ability to appropriately transfer flexural loads.

Long-term deflection of connected panels ( $\delta_{\text {Quasi }}$ ) was also estimated with Eq. (1), by also assuming for $\alpha$ and $\gamma_{\text {Creep }}$ the values already considered, namely, 0.3 and 2.52 , respectively. For the two and three connected panels a value, respectively, of $5.4 \mathrm{~mm}$ and $5.3 \mathrm{~mm}$ was obtained for $\delta_{\text {Quasi }}$, which fulfils the serviceability limit requirement recommended by $\mathrm{CNR}^{42}(2700 / 250=10.8 \mathrm{~mm})$. Moreover, the maximum strain measured in the two and three connected panels for the ULS load was $334 \mu \varepsilon$ and $426 \mu \varepsilon$, respectively. These strains are significantly lower than the ultimate strain measured in GFRP skins material characterization $(12188 \mu \varepsilon)$.

\subsection{Loading test on modular prototype}

For a more comprehensive analysis of the results obtained in the test with the floor prototype, it was verified opportune to group the results measured in LVDTs and strain gauges. The arrangement of these groups takes into account the structural symmetry conditions in order to determine the average results in each group. Hence, regarding to LVDTs (all subsequent LVDTs names are related to Fig. 7b), Group DI corresponds to the LVDT placed at the centre of the middle panel (D4). Group DII consists of the LVDTs placed at the middle of the interior edges of the panels (D2-D3 and D5-D6). Group DIII are composed of the LVDTs placed at the centre of the lateral panels (D1 and D7). Group DIV is formed by the LVDTs disposed in the transverse beams (D10 and D11). Group DV corresponds to the LVDTs placed on the longitudinal beams (D8 and D9). Similarly, for the case of strain gauges, the results were collected in the following seven groups (Fig. 7b): Group SI (S12 and S13), Group SII (S4), Group SIII (S2 and S6), Group SIV (S1 and S7), Group SV (S14 and S15), Group SVI (S9) and Group SVII (S8 and S11). Table 2 lists average values registered for each of the mentioned groups at the end of the test (i.e. for a load applied equal to the ULS conditions), while the registered deflection-time and strain-time relations are depicted in Fig. 13.

The end of the loading operation corresponds to the instant when the measured entity remained almost constant. Both deflection-time and strain-time relationships revealed that the floor prototype developed a linear behaviour for the entire applied loading process. The higher deflection registered in the centre of the middle panel (LVDT of Group DI) was expected since this corresponds to the centre of the floor, in the panel that was mainly 
supported only by two edges. Conversely, since the lateral panels were supported along three edges, the deflection in the centre of these panels (Group DIII) were much smaller. The deflection in the groups DI and DIII indicates the floor panels presented a two-way bending behaviour, in longitudinal (parallel to the direction of the connection between panels) and transverse directions, being bending in the longitudinal direction more pronounced than in transverse direction. Confirmation of difference in the load transmission on the panels may be also seen by comparing results of the fourth and fifth groups of LVDTs, whose analysis showed that the load was not distributed equally by all beams: transverse beams registered nearly a triple deflection of that measured in longitudinal beams.

Table 2 Registered deflections and strains in the floor prototype.

\begin{tabular}{lccccccc}
\hline & Group I & Group II & Group III & Group IV & Group V & Group VI & Group VII \\
\hline Deflection (mm) & -33.4 & -31.0 & -21.6 & -13.8 & -4.6 & -- & -- \\
Strain ( $\mu$ strain) & 786.2 & 637.5 & 569.3 & 420.1 & 235.7 & 101.4 & 27.3 \\
\hline
\end{tabular}

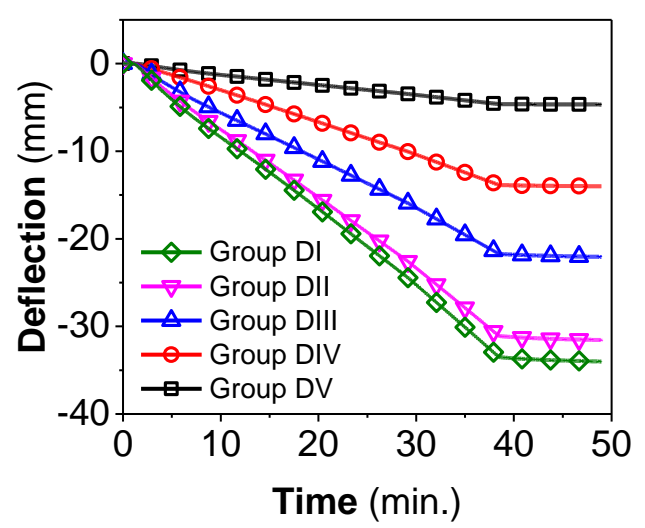

(a)

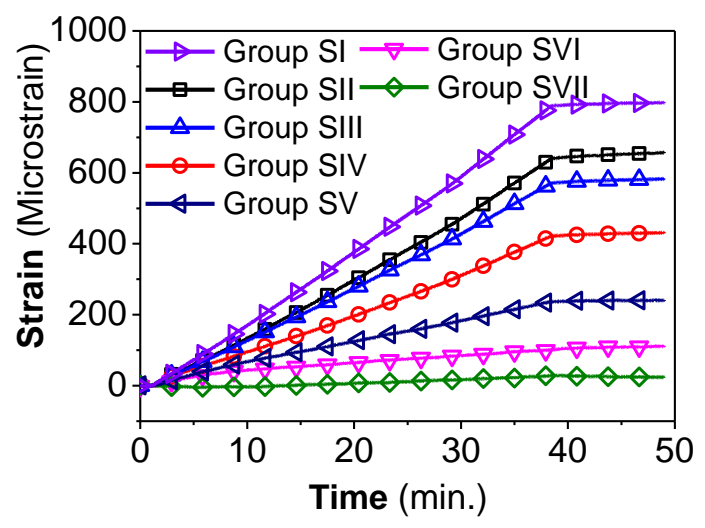

(b)

Fig. 13. Floor prototype flexural performance: (a) deflection versus time; (b) strain versus time. 
Furthermore, strains registered on the transverse beams (Group SI) were higher than other measured strains (Group SV). This demonstrates that the load was not uniformly distributed, but transverse beams carried out more load than longitudinal beams, in which the average strain recorded was $30 \%$ lower. Comparing the strain measured in the strain gauge located in the centre of the middle panel in longitudinal direction (Group SII), with those recorded in the strain gauge placed in the middle of the other two panels, also in longitudinal direction (Group SIV), a difference of nearly $65 \%$ was registered. This result is equivalent to what was observed with deflections, and is explained by the support conditions, since middle panel supported on two opposite edges, while exterior ones behaved as panels mainly supported on three edges. Because of this, a similar result is obtained when comparing gauges in transverse direction (Strains - Group SVI and Strains - Group SVII).

The long-term maximum deflection of the prototype may be estimated considering the experimental results and using Eq. (1). For this purpose, and for the deflection corresponding to the ULS condition $\left(2.4 \mathrm{kN} / \mathrm{m}^{2}\right)$, deflection registered on the transverse beams $(13.8 \mathrm{~mm})$ should be subtracted from the deflection registered in the middle panel $(33.4 \mathrm{~mm})$, resulting a value of $19.6 \mathrm{~mm}$. Substituting this value in Eq. (1), an estimated longterm deflection of $9.9 \mathrm{~mm}$ is obtained. Taking into account that in the prototype the length of panels is equal to $3000 \mathrm{~mm}$, the estimated value fulfils the deflection criterion recommended by $\mathrm{CNR}^{42}(\leq L / 250=12.0 \mathrm{~mm})$. As in the other conducted tests, the GFRP strains were significantly lower than the ultimate strain measured in coupons of GFRP skins.

\section{Analytical assessment}

In the following subsections the flexural behaviour of the tested panels is estimated by applying available theoretical formulations, and using the properties of the constituent materials recorded experimentally.

\subsection{Failure mode of the single sandwich floor panel}

Interaction between GFRP skin and PU foam core can be treated using Allen's formula by invoking the concept of Winkler hypothesis ${ }^{45}$. In that model the GFRP skin is modelled as infinitely long strut supported on an elastic medium (the core of the panel). Two kinds of stresses can be developed: interfacial stress $\left(\sigma_{\text {in }}\right)$, and critical wrinkling stress $\left(\sigma_{c r}\right)^{44,47,48}$. Interfacial stress is defined as:

$$
\sigma_{\text {in }}=0.07 \pi^{2} f(\theta) E_{c}
$$


where $\theta$ depends of the core thickness $\left(t_{c}\right)$ and half-wave length of $l$ is given by $\theta=\frac{\pi t_{c}}{l}, E_{c}$ is the elastic modulus of the PU foam. $f(\theta)$ is a function of the core Poisson's ratio $\left(v_{c}\right)$ and $\theta$. The value of $f(\theta)$ depends on skin wrinkling mode. Three cases of skin wrinkling modes were defined ${ }^{45}$ : Case I - represents a sandwich panel in which wrinkling occurred in the compression skin; Case II - deals with antisymmetric wrinkling; and, Case III - considers symmetric wrinkling. In this research Case I was considered the most appropriate since only one face skin was debonded. Accordingly, Eq. (3) was proposed for this purpose as:

$f(\theta)=\left(\frac{2}{\theta}\right) \times\left(\frac{\left(3-v_{c}\right) \times \sinh \theta \times \cosh \theta+\left(1+v_{c}\right) \times \theta}{\left(1+v_{c}\right) \times\left(3-v_{c}\right)^{2} \times \sinh ^{2} \theta-\left(1+v_{c}\right)^{3} \times \theta^{2}}\right)$

Debonding occurs when the interfacial tensile strength $\left(\sigma_{i n}\right)$ exceeds the tensile strength of the PU foam core.

Regarding the critical wrinkling stress, it is determined by the following equation:

$\sigma_{c r}=\left(\frac{E_{c}}{t_{f}}\right) \times t_{c} \times f(\theta)+\frac{E_{f}}{12} \times\left(\frac{\theta}{t_{c}}\right)^{2} \times t_{f}{ }^{2}$

where $t_{f}$ and $E_{f}$ are the thickness and the elastic modulus of the GFRP skin, respectively.

The previous equations were applied to the single panel tested under the four-point bending configuration (see Sections 3.3 and 4.3). In the experimental program it was observed that, the length of the debonded part was equal to the PU thickness. Based on this, interfacial tensile stress, $\sigma_{i n}$, was obtained by a value of $0.77 \mathrm{MPa}$ using Eqs. (2) and (3). A comparison of this value with the maximum tensile strength of PU foam core $\left(\sigma_{c t}\right)$ experimentally determined (see Table 1) of 0.49 MPa reveals the separation between PU foam core and GFRP skin was caused by the attainment of the tensile capacity of the PU.

From Eq. (4) a critical wrinkling stress ( $\sigma_{c r}$ ) of $62.6 \mathrm{MPa}$ was determined for the GFRP skin. Based on strain values measured in S5 (Fig. 5b), a compressive stress value of 25.1 MPa was calculated on the GFRP skin (the value was computed assuming the modulus of elasticity experimentally recorded). Comparing the experimental and the theoretical values for the critical wrinkling stress, it can be observed that, these two values differ by a factor of nearly 2.5 . This stress relation was also found in previously performed tests ${ }^{44,49,50}$. Due to lack of predictive performance of Eq. (4) an empirical expression ${ }^{44}$ was proposed as expressed by Eq. (5):

$\sigma_{c r}=0.42 \times E_{f}^{1 / 3} E_{c}^{2 / 3}$ 
By applying this equation, a critical wrinkling stress of $25.5 \mathrm{MPa}$ was obtained, which is a value quite close to the one obtained experimentally (25.1 MPa), demonstrating the good predictive performance of Eq. (5).

\subsection{Effects of the U-shape GFRP profiles in the single sandwich panels}

First-order Shear Deformation Theory (FSDT) may be employed to evaluate flexural performance of a single sandwich panel. In this theory, some hypotheses are assumed, such as considering the panel components are formed by isotropic materials, and assuming perfect bond between constituent components. Besides, the total deflection of the sandwich panel $\left(\delta_{\text {Total }}\right)$ can be estimated by considering the simultaneous contribution of bending and shear deformation:

$\delta_{\text {Total }}=\delta_{b}+\delta_{s}$

where $\delta_{b}$ and $\delta_{s}$ are the deflections due to the bending and shear, respectively. Eq. (6) could be expressed in the following form:

$\delta_{\text {Total }}=\int_{0}^{L} \frac{M_{u} M_{L}}{E I} d x+\int_{0}^{L} \frac{V_{u} V_{L}}{k G A}$

where the first and second terms of the right part of this equation provide the deflection due to bending and shear, respectively. In Eq. (7) the $M_{u}\left(V_{u}\right)$ and $M_{L}\left(V_{L}\right)$ are the bending moments (shear forces) due to a unit load and the actual load, respectively.

By developing Eq. (7) in terms of providing the midspan deflection of a sandwich panel subjected to a uniform loading, it is obtained:

$\delta_{\text {Total }}=\frac{5 q L_{s}^{4}}{384(E I)_{e q}}+\frac{q L_{s}^{2}}{8 K(G A)}$

where $q, L_{s},(E I)_{e q},(G A)$ and $K$ are the uniform distributed load, span length, equivalent flexural stiffness, shear stiffness and shear correlation factor, respectively. The coefficient $K$ was assumed equal to 1.0 in this study ${ }^{51}$. For the present sandwich panel, the equivalent flexural stiffness is obtained by the following equation:

$(E I)_{e q}=b E_{f}\left[\frac{t_{f}{ }^{3}}{6}+2 t_{f}\left(\frac{t_{f}}{2}+\frac{t_{c}}{2}\right)^{2}\right]+\frac{n E_{U}}{12}\left[b_{u} t_{c}{ }^{3}-\left(b_{u}-t_{u}\right)\left(t_{c}-2 t_{u}\right)^{3}\right]$ 
where $b$ is the width of the panel, $n$ is the number of the U-shape GFRP profiles (both located in the interior of the panel and at the edges), and $E_{U}, t_{u}, b_{u}$ are the Young's modulus, thickness and width of those profiles, respectively.

In Table 3 is compared the midspan deflection obtained from Eq. (8) and measured experimentally. A very good agreement between experimental and analytical values is observed, showing an adequate precision of FSDT in estimating the total deflection of the sandwich panels.

Table 3 Results obtained in the flexural test performed on single composite sandwich floor panels.

\begin{tabular}{clcc}
\hline & \multicolumn{3}{c}{$\delta$ Total $(\mathrm{mm})$} \\
\cline { 2 - 4 } & \multicolumn{2}{c}{ SLS } & \multicolumn{1}{c}{ ULS } \\
\cline { 2 - 4 } Experimental & FP1 & 7.3 & 11.2 \\
& FP3 & 7.7 & 11.2 \\
& FP4 & 7.5 & 11.4 \\
& Average & 7.4 & 11.2 \\
\hline \multirow{5}{*}{ Analytical } & Flexural deflection & 7.5 & $\mathbf{1 1 . 2}$ \\
& Shear deflection & 0.2 & 10.4 \\
\cline { 2 - 4 } & Total deflection & $\mathbf{7 . 2 ( - 4 . 2 \% )}$ & $\mathbf{1 0 . 4 ( - 7 . 7 \% )}$ \\
\hline
\end{tabular}

Note: the values between parentheses are the relative difference between the analytical predictions and the experimental results.

Fig. 14 shows the influence of the number of U-shape GFRP profiles $(n)$ on the midspan deflection of the sandwich panel, having been adopted values of $n$ varying from 0 to 4 . As can be observed, when deflection is computed for a panel without U-shape GFRP profile $(n=0)$ and for a panel with one U-shape GFRP profile $(n=$ 1), a sudden decrease in the deflection of nearly $42 \%$ takes place. By using more than one U profile, the total deflection tends to decrease almost linearly with the increase of the number of GFRP profiles. Moreover, the relative contribution of bending $(\mathrm{M})$ and shear $(\mathrm{V})$ on the total deflection (indicated on the top right corner of Fig. 14) shows that the contribution of the shear deformation decreases with the increase of the number of GFRP profiles applied. When GFRP are not applied $(n=0)$ the contribution of bending and shear for the total deformation is $60 \%$ and $40 \%$, respectively, while when 4 GFRP profiles are adopted this relative contribution is $97 \%$ and $3 \%$. Thus, for the panel designed, the dominate deformation is flexural and not shear, since four Ushape GFRP profiles were used in each panel (two interior and two at edges) that are working as ribs, providing high shear stiffness (GA) to the panel. 


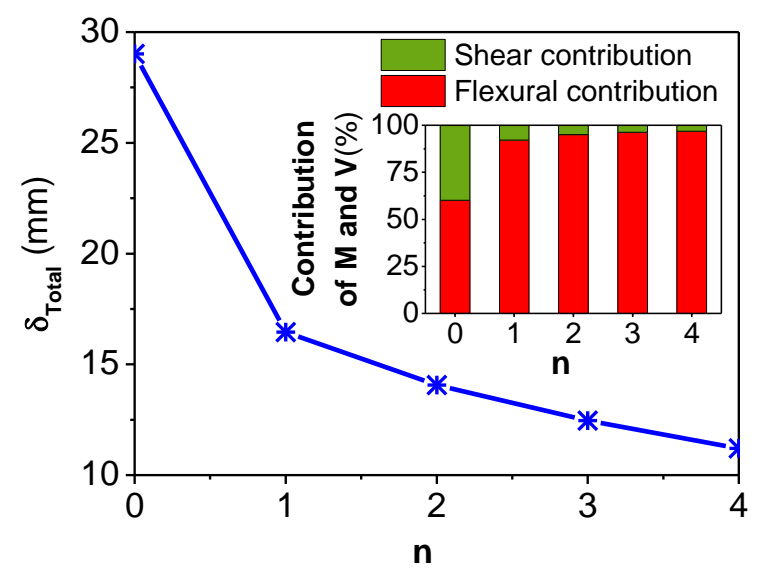

Fig. 14. Influence of the number of U-shape GFRP profiles on the total midspan deflection of the sandwich panel.

The load-deflection behaviour of the tested single sandwich panel under four-point bending test configuration was also analytically determined by using FSDT and considering the same assumptions. Eq. (10) gives the total deflection for a four-point load configuration,

$\delta_{\text {Total }-4 P B T}=\frac{P a}{(E I)_{e q}}\left(\frac{L_{s}^{2}}{8}-\frac{a^{2}}{6}\right)+\frac{P a}{K G A}$

where $P$ is the applied line load, $L_{s}$ is the span (equal to $2700 \mathrm{~mm}$ ), $a$ is the shear span (equal to $850 \mathrm{~mm}$ ), $(E I)_{e q}$ is the equivalent flexural stiffness determined according to Eq. (9) $\left(159.3 \mathrm{kN} \cdot \mathrm{m}^{2}\right)$, and $G A$ is the shear stiffness $(6147.4 \mathrm{kN})$. By adopting these values, a midspan deflection of $62.0 \mathrm{~mm}$ was calculated, which is in good agreement with the experimental result, since the difference is $1.6 \%$.

\subsection{Efficiency of the proposed connection system between panels}

The Eqs. (9) and (10) were also applied to predict the midspan deflection of the connected panels (see Sections 3.4 and 4.4), and the results are presents in Table 4, which also include the flexural and shear stiffness values. Additionally, analytical results of a unique slab (a slab formed by the same number of U-shape GFRP profiles as the connected panels but assuming continuity between the panels) with the same dimensions and configuration of the connected panels were obtained in order to evaluate the efficiency of the proposed connection.

The results of Table 4 indicate an acceptable predictive performance for the analytical expressions, since a relative difference of $2.2 \%$ and $2.4 \%$ for the, respectively, two and three connected sandwich panels, was 
obtained. Comparison of analytical values between connected panels and a unique slab shows that using the proposed connection system results in decreasing the midspan deflection in $7.2 \%$ and $9.5 \%$ for two and three panels, respectively. This is the consequence of the influence of using the connector profile (see Fig. 2c), which increases the flexural stiffness and shear stiffness of the connected panels.

Table 4 Flexural response of connected panels and unique sandwich slab.

\begin{tabular}{|c|c|c|c|c|c|c|c|}
\hline \multirow{3}{*}{$\begin{array}{l}\mathrm{N} \text {. of } \\
\text { panels }\end{array}$} & \multicolumn{4}{|c|}{ Connected panels } & \multicolumn{3}{|c|}{ Continuous slab ${ }^{1}$} \\
\hline & \multicolumn{2}{|c|}{ Panel's properties } & \multicolumn{2}{|c|}{ Midspan deflection } & \multicolumn{2}{|c|}{ Panel's properties } & \multirow{2}{*}{$\begin{array}{c}\text { Midspan deflection } \\
\text { Ana. } \\
(\mathrm{mm})\end{array}$} \\
\hline & $\mathrm{EI}\left(\mathrm{kN} \cdot \mathrm{m}^{2}\right)$ & $\mathrm{GA}(\mathrm{kN})$ & $\begin{array}{l}\text { Exp. } \\
\text { (mm) }\end{array}$ & Ana. (mm) & $\mathrm{EI}\left(\mathrm{kN} \cdot \mathrm{m}^{2}\right)$ & $\mathrm{GA}(\mathrm{kN})$ & \\
\hline Two & 338.3 & 16494.8 & 9.8 & $10.5(6.7 \%)^{2}$ & 318.6 & 12294.8 & $11.8(11.0 \%)^{3}$ \\
\hline Three & 517.3 & 26842.3 & 9.3 & $10.3(9.7 \%)^{2}$ & 477.9 & 18442.3 & $11.2(8.0 \%)^{3}$ \\
\hline
\end{tabular}

Notes: ${ }^{1}$ slab without connections; ${ }^{2}$ relative difference between the analytical predictions and the experimental results; ${ }^{3}$ relative difference between continuous slab and connected panels

\subsection{Residential modular prototype}

As demonstrated in Section 5.2, for the present solution of sandwich panels, the contribution of shear deformation for the total deflection is marginal. Hence, neglecting shear effects in the evaluation of the total deflection of the modular prototype seems perfectly acceptable. Accordingly, the classical laminate plate theory (CLPT) can be used to analytically predicte the floor prototype deformational behaviour.

The prototype was considered to be subjected to an uniform distributed load. In addition, it was considered that the sandwich panels were subjected to two kinds of support conditions: (i) the exterior panels (FP1 and FP3 see Fig. 7) were considered as simply supported panels along three edges, while the other edge of these panels was assumed free of any displacement restriction, (ii) middle panel (FP2 - see Fig. 7) was considered as a panel supported along only two edges, being the other two edges free of any displacement restriction.

Accordingly, Eqs. (11) and (12) are proposed for calculating the midspan deflection in panels FP1-FP3 (exterior panel) and FP2 (interior panel), respectively. Comprehensive information of the derivation methods can be consulted elsewhere ${ }^{45,47,52}$.

$$
\begin{aligned}
& w_{\text {max }}=0.01302 \frac{q L^{4}}{(E I)_{e q}} \\
& w_{\text {max }}=0.0071 \frac{q L^{4}}{(E I)_{e q}}
\end{aligned}
$$

where $q$ is the uniform pressure load, $L$ is the length of the panel. From Eq. (11) a deflection at midspan of the middle panel (maximum deflection) of $18.7 \mathrm{~mm}$ was computed for a uniform load of $2.4 \mathrm{kN} / \mathrm{m}^{2}$ and a flexural 
stiffness determined from Eq. (9). This value is close to the maximum slab deflection of $19.6 \mathrm{~mm}$ which experimentally was obtained. In the case of exterior panels, the maximum deflection was occurred at the middle span of the free edge, and resulted in a value of $10.2 \mathrm{~mm}$, calculated based on Eq. (12). Experimental observations showed a deflection of $12.6 \mathrm{~mm}$. Therefore, experimental results obtained in the exterior panels are also coherent with the analytical ones. The differences found can be explained by the fact that the continuity between panels were neglected in this assessment.

Finally, load distribution factor $\left(\alpha_{L D F}\right)$ was evaluated to compute the working proportionality of the floor prototype in each longitudinal and transverse direction. This factor was assessed on the longitudinal and transverse GFRP beams according to Eq. (13).

$\delta_{L b}=\alpha_{L D F} \times\left(\delta_{L b}+\delta_{T b}\right)$

where $\delta_{L b}$ and $\delta_{T b}$ are the experimentally measured beam deflection in ULS condition in the longitudinal and transversal direction directions respectively

Since deflection values experimentally measured on the transverse and longitudinal beams was $13.8 \mathrm{~mm}$ and $4.6 \mathrm{~mm}$, respectively, the value of $\alpha_{L D F}$ was calculated as 0.75 and 0.25 in transverse and longitudinal beams, respectively.

\section{Conclusion}

This paper has presented a novel modular prototype floor to be used as a part of an emergency house. The prototype consists of a skeleton of GFRP tubular pultruded profiles, and a floor formed by three sandwich panels with GFRP skins and a PU foam core. A fitting connection system is utilized to appropriately assemble the different components. The developed prototype is capable of being prefabricated and easily transported to the site, and rapidly installed. This functionality illustrates the high potentiality of this system to be used in prefabricated emergency houses.

An experimental program has been conducted, studying the behavior of a single floor panel, two and three connected panels and the whole modular floor prototype, subjected to residential service and ultimate loads. Additionally, an analytical assessment has been developed to conduct a deeper study of the failure mechanisms, the influence of placing U-shape GFRP profiles inside the panels, the efficiency of the connections between 
panels and the deformational behavior of the prototype. The following concluding remarks were drawn from this work:

1. The prototype demonstrates a high potentiality to be integrated in the production lines for temporary residential building, and more specifically to be used in places with high demanding for habitation due to natural disasters. The assembly/disassembly process is simple and fast due to the lightness of the components and simplicity of the connections.

2. For the considered load levels, typical of a building structure, the sandwich panels have presented a linear-elastic behaviour. Their maximum deflection under service loads, taking into account the creep effects, fulfils the requirement established by standards.

3. The ultimate load carrying capacity of the sandwich panels was substantially greater than the design demand levels. The failure has occurred due to a local outward buckling, known as wrinkling. The failure has started when the outward tensile stress between the GFRP skin and PU foam core has attained the tensile strength of the PU. The debonding has propagated towards the centre of the panel, leading to a loss of integrity between GFRP skin and PU foam core.

4. The behaviour of connected two and three sandwich panels has exhibited adequate flexural performances and has fulfilled the requirements in both SLS and ULS, in terms of deflection and strain. Moreover, the proposed connection system has demonstrated to be effective in transferring loads between the panels, guaranteeing deformation compatibility.

5. The floor prototype has presented a flexural behaviour more predominant in one direction. However, beam-panel and panel to panel connectors contributed for the development of a certain level of transverse curvature, therefore the floor panels have behaved as a two-way spanning slab with load distribution factor of around $75 \%$ and $25 \%$ for the longitudinal and transverse supporting beams, respectively. The excellent performance showed by the proposed prototype, along with the fulfilment of long-term behaviour requirements, highlighted the potential capacity of the proposed system for being used as a temporary floor building.

6. A theoretical prediction employing Winkler hypothesis and utilizing mechanical properties of the constituent materials were employed to evaluate the failure mode of single sandwich panel. Accordingly, two kinds of stresses, namely interfacial out-of-plane stress and critical wrinkling stress were evaluated. It 
was shown that the interfacial out-of-plane stress between the PU foam core and the GFRP skins occur has exceeded the tensile strength of the PU foam, justifying the debonding of the top GFRP skin observed experimentally. The calculated critical wrinkling stress based on the proposed equations was in good agreement with the experimental measured values.

7. The first-order shear deformation theory was employed to predict the deformational behavior of single sandwich panel, as well as connected sandwich panels. A very good agreement between the experimental and analytical values was observed. The importance of using U-shape GFRP profiles inside the sandwich panels as ribs for increasing the flexural stiffness of the panel was clearly observed. The analytical analysis has showed that when no U-shape GFRP profile is used the contribution of flexural and shear deformation for the total deflection of the panels is $60 \%$ and $40 \%$, respectively. However, the contribution of the shear deformation for the total deflection of the panels has decreased significantly with the increase of the number of the U-shape GFRP profiles. For the four profiles per panel (the number used in the developed panels), the shear deformation contribution for the total deflection was reduced to $3 \%$. Additionally, it was observed that using a connector in two and three connected panels resulted in decreasing middle span deflection when compared to a unique panel.

\section{Acknowledgements}

This work is part of the research project ClickHouse - Development of a prefabricated emergency house prototype made of composites materials, involving the company ALTO - Perfis Pultrudidos, Lda., CERis/Instituto Superior Técnico and ISISE/University of Minho, supported by FEDER funds through the Operational Program for Competitiveness Factors - COMPETE and the Portuguese National Agency of Innovation (ADI) - project no. 38967. Special thanks are given to company ALTO who manufactured all the elements (GFRP profiles and sandwich panels) involved in this work. The authors also want to express their gratitude to engineer Luís Oliveira, for his invaluable collaboration, help and support in this research. The fourth author wish to acknowledge the grant SFRH/BSAB/114302/2016 provided by FCT.

\section{References}

1. Johnson C. Impacts of prefabricated temporary housing after disasters: 1999 earthquakes in Turkey. Habitat International 2007; 31: 36-52. DOI: http://dx.doi.org/10.1016/j.habitatint.2006.03.002. 
2. Arslan $\mathrm{H}$ and Cosgun N. Reuse and recycle potentials of the temporary houses after occupancy: Example of Duzce, Turkey. Building and Environment 2008; 43: 702-709.

3. Barakat S. Housing reconstruction after conflict and disaster.: London: Overseas Development Institute., 2003.

4. Dodoo A and Gustavsson L. Life cycle primary energy use and carbon footprint of wood-frame conventional and passive houses with biomass-based energy supply. Applied Energy 2013; 112: 834-842. DOI: http://dx.doi.org/10.1016/j.apenergy.2013.04.008.

5. Datin PL and Prevatt DO. Using instrumented small-scale models to study structural load paths in wood$\begin{array}{llllll}\text { framed } & \text { buildings. } & \text { Engineering } & \text { Structures } & \text { 2013; } & \text { 54: }\end{array}$ http://dx.doi.org/10.1016/j.engstruct.2013.03.039.

6. Imperadori M, Salvalai G and Pusceddu C. Air Shelter House Technology and its Application to Shelter Units: the Case of Scaffold House and Cardboard Shelter Installations. Procedia Economics and Finance 2014; 18: 552-559. DOI: http://dx.doi.org/10.1016/S2212-5671(14)00975-7.

7. Ljunggren F and Ågren A. Potential solutions to improved sound performance of volume based lightweight multi-storey timber buildings. Applied Acoustics 2011; 72: 231-240. DOI: http://dx.doi.org/10.1016/j.apacoust.2010.11.007.

8. Winandy JE, Hunt JF, Turk C, et al. Emergency housing systems from three-dimensional engineered fiberboard : temporary building systems for lightweight, portable, easy-to-assemble, reusable, recyclable, and biodegradable structures. 2006. Madison, WI: U.S. Department of Agriculture, Forest Service, Forest Products Laboratory.

9. Zenkert D. An intoduction to sandwich construction. Stockholm: Cradley Heath, Warley:Engineering Materials Advisory Services., 1995.

10. Vinson JR. The behavior of sandwich structures of isotropic and composite materials. United States of America: Technomic publishing company,Inc, 1999.

11. Kootsookos A and Burchill PJ. The effect of the degree of cure on the corrosion resistance of vinyl ester/glass fibre composites. Composites Part A: Applied Science and Manufacturing 2004; 35: 501-508. DOI: http://dx.doi.org/10.1016/j.compositesa.2003.08.010. 
12. Nguyen $\mathrm{CH}$, Chandrashekhara $\mathrm{K}$ and Birman V. Multifunctional thermal barrier coating in aerospace sandwich panels. Mechanics Research Communications 2012; 39: 35-43. DOI: http://dx.doi.org/10.1016/j.mechrescom.2011.10.003.

13. Allard JF and Atalla N. Propagation of Sound in Porous Media: Modelling Sound Absorbing Materials. 2009, p.1-358.

14. Sousa JM, Correia JR, Cabral-Fonseca S, et al. Effects of thermal cycles on the mechanical response of pultruded GFRP profiles used in civil engineering applications. Composite Structures 2014; 116: 720-731. DOI: http://dx.doi.org/10.1016/j.compstruct.2014.06.008.

15. Correia JR, Cabral-Fonseca S, Branco FA, et al. Durability of pultruded glass-fiber-reinforced polyester profiles for structural applications. Mechanics of Composite Materials 2006; 42: 325-338.

16. Rizkalla S, Lucier G and Dawood M. Innovative use of FRP for the precast concrete industry. Advances in Structural Engineering 2012; 15: 565-574.

17. Oppe MW and Knippers J. Application of bolted connections in fibre-reinforced polymers. Proceedings of the Institution of Civil Engineers: Structures and Buildings 2011; 164: 321-332.

18. Shawkat W, Honickman H and Fam A. Investigation of a novel composite cladding wall panel in flexure. Journal of Composite Materials 2008; 42: 315-330.

19. Sharaf T, Shawkat W and Fam A. Structural performance of sandwich wall panels with different foam core densities in one-way bending. Journal of Composite Materials 2010; 44: 2249-2263.

20. Correia JR, Garrido M, Gonilha JA, et al. GFRP sandwich panels with PU foam and PP honeycomb cores for civil engineering structural applications: Effects of introducing strengthening ribs. International Journal of Structural Integrity 2012; 3: 127-147.

21. Keller T, Haas C and Valĺe T. Structural concept, design, and experimental verification of a glass fiberreinforced polymer sandwich roof structure. Journal of Composites for Construction 2008; 12: 454-468.

22. Escusa G, Garzón-Roca J, Abdolpour H, et al. CARACTERIZAÇÃO EXPERIMENTAL DO COMPORTAMENTO MECÂNICO DE PAINÉIS SANDWICH COM LÂMINAS DE GFRP E NÚCLEO DE POLIURETANO. JPEE. Lisboa2014. 
23. Mousa MA and Uddin N. Global buckling of composite structural insulated wall panels. Materials \& Design 2011b; 32: 766-772. DOI: http://dx.doi.org/10.1016/j.matdes.2010.07.026.

24. Abdolpour H, Escusa G, Sena-Cruz JM, et al. Axial Performance of Jointed Sandwich Wall Panels. Journal of Composites for Construction 2017: 12. DOI: 10.1061/(ASCE)CC.1943-5614.0000785.

25. Garrido M, Correia JR, Keller T, et al. Adhesively bonded connections between composite sandwich floor panels for building rehabilitation. Composite Structures 2015; 134: 255-268. DOI: http://dx.doi.org/10.1016/j.compstruct.2015.08.080.

26. Abdolpour H, Zamanzadeh $\mathrm{Z}$ and Behravesh A. Estimation of statically equivalent seismic forces of single layer reticular domes. 5th International Structural Engineering and Construction Conference Las Vegas, USA2009.

27. Zamanzadeh Z, Abdolpour $\mathrm{H}$ and Behravesh A. Investigating the buckling behavior of single layer dome form of space structures. 5th International Structural Engineering and Construction Conference Las Vegas, USA2009.

28. Standard Test Method for Tensile Properties of Polymer Matrix Composite Materials.

29. Standard Test Method for Flatwise Compressive Properties of Sandwich Cores.

30. Standard Test Method for Flatwise Tensile Strength of Sandwich Constructions.

31. Garrido M. Composite sandwich panel floors for building rehabilitation. INSTITUTO SUPERIOR TÉCNICO, UNIVERSIDADE DE LISBOA, 2015.

32. Standard Test Method for Tensile Strength of Concrete Surfaces and the Bond Strength or Tensile Strength of Concrete Repair and Overlay Materials by Direct Tension (Pull-off Method)

33. Standard Test Method for Tensile Properties of Plastics.

34. United Nations High Commissioner for Refugees

35. Standard Test Method for Flexural Properties of Sandwich Constructions.

36. Zenkert D, Shipsha A and Persson K. Static indentation and unloading response of sandwich beams. Composites Part B: Engineering 2004; 35: 511-522. DOI: http://dx.doi.org/10.1016/j.compositesb.2003.09.006. 
37. Petras A and Sutcliffe MPF. Indentation resistance of sandwich beams. Composite Structures 1999; 46: 413424. DOI: http://dx.doi.org/10.1016/S0263-8223(99)00109-9.

38. Rizov V, Shipsha A and Zenkert D. Indentation study of foam core sandwich composite panels. Composite Structures 2005; 69: 95-102. DOI: http://dx.doi.org/10.1016/j.compstruct.2004.05.013.

39. Petras A and Sutcliffe MPF. Indentation failure analysis of sandwich beams. Composite Structures 2000; 50: 311-318. DOI: http://dx.doi.org/10.1016/S0263-8223(00)00122-7.

40. Borsellino C, Calabrese L and Valenza A. Experimental and numerical evaluation of sandwich composite structures. Composites Science and Technology 2004; 64: 1709-1715. DOI: http://dx.doi.org/10.1016/j.compscitech.2004.01.003.

41. Fam A and Sharaf T. Flexural performance of sandwich panels comprising polyurethane core and GFRP skins and ribs of various configurations. Composite Structures 2010; 92: 2927-2935. DOI: http://dx.doi.org/10.1016/j.compstruct.2010.05.004.

42. CNR, Guide for the Design and Construction of Structures made of FRP Pultruded Elements.

43. Abdolpour H, Garzón-Roca J, Escusa G, et al. Development of a composite prototype with GFRP profiles and sandwich panels used as a floor module of an emergency house. Journal of Composite Structures: Elsevier, 2016.

44. Mousa MA and Uddin N. Flexural behavior of full-scale composite structural insulated floor panels. Advanced Composite Materials 2011a; 20: 547-567.

45. Allen GH. Analysis and Design of Structural Sandwich Panels. . London: Pergmon Press, 1969.

46. Zenkert D. The Handbook of Sandwich Construction. London, United Kingdom: Chameleon Press Ltd., 1997.

47. Carlsson LA and Kardomateas GA. Structural and Failure Mechanics of Sandwich Composites. New York Springer, 2011.

48. Mousa MA and Uddin N. Structural behavior and modeling of full-scale composite structural insulated wall panels. Engineering Structures 2012; 41: 320-334. DOI: http://dx.doi.org/10.1016/j.engstruct.2012.03.028. 
49. The Buckling of Sandwich-Type Panels. Journal of the Aeronautical Sciences 1945; 12: 285-297. DOI: $10.2514 / 8.11246$.

50. Mousa MA and Uddin N. Debonding of composites structural insulated sandwich panels. Journal of Reinforced Plastics and Composites 2010. DOI: 10.1177/0731684410380990.

51. Eskandari H. The effect of shear deformation on material selection for bending components. Materials \& Design 2003; 24: 143-149. DOI: http://dx.doi.org/10.1016/S0261-3069(02)00125-5.

52. Timoshinko S. Theory of plates and shells. New York: McGRAW-HILL Book company, 1989.

53. Ginjeira do Nascimento J. Transitional architecture in emergency scenarios. Clickhouse case study: modular shelter made of advanced composite materials. Técnico Lisboa, Portugal, 2015. 